NBER WORKING PAPER SERIES

ARE TRADE AGREEMENTS GOOD FOR YOU?

\author{
Giovanni Maggi \\ Ralph Ossa \\ Working Paper 27252 \\ http://www.nber.org/papers/w27252
NATIONAL BUREAU OF ECONOMIC RESEARCH
1050 Massachusetts Avenue
Cambridge, MA 02138
May 2020

We thank seminar participants at Banco de Espana, Georgetown University, Harvard University, IFN Stockholm, Lund University, New York University, Sapienza University of Rome, Stanford University, Swiss National Bank, University of Geneva, University of Turin, University of Zurich and Yale University, as well as participants in the Princeton IES Summer Workshop and the NBER ITI Summer Institute. We thank Richard Baldwin, Arnaud Costinot, Kyle Bagwell, Rod Ludema, Monika Mrazova, Francesco Passarelli, Dani Rodrik, Robert Staiger, Guido Tabellini, and especially Nuno Limao and Ivan Werning for helpful comments. Maggi gratefully acknowledges funding from the National Science Foundation grant No.1949374. Ossa gratefully acknowledges funding from the European Research Council (ERC) under the European Union's Horizon 2020 research and innovation program (grant agreement No 819394). The usual disclaimer applies. The views expressed herein are those of the authors and do not necessarily reflect the views of the National Bureau of Economic Research.

NBER working papers are circulated for discussion and comment purposes. They have not been peerreviewed or been subject to the review by the NBER Board of Directors that accompanies official NBER publications.

(C) 2020 by Giovanni Maggi and Ralph Ossa. All rights reserved. Short sections of text, not to exceed two paragraphs, may be quoted without explicit permission provided that full credit, including $\odot$ notice, is given to the source. 
Are Trade Agreements Good For You?

Giovanni Maggi and Ralph Ossa

NBER Working Paper No. 27252

May 2020

JEL No. F13,F15,F50

\begin{abstract}
We examine how deep agreements on domestic regulations affect welfare in a world where such agreements are influenced by producer lobbies. The answer to this question depends in a critical way on whether the agreement focuses on product standards or on production regulations. International cooperation on product standards can decrease welfare, and this is more likely to happen when producer lobbies are stronger. On the other hand, international cooperation on production regulations tends to enhance welfare when lobbying pressures are strong. A key determinant of the welfare impact of deep agreements is whether the interests of producer lobbies in different countries are aligned or in conflict: the former situation tends to occur in the case of product standards, while the latter situation tends to occur in the case of production regulations.
\end{abstract}

\title{
Giovanni Maggi
}

Department of Economics

Yale University

37 Hillhouse Avenue Rm 27

New Haven, CT 06511

and FGV/EPGE-Rio

and also NBER

giovanni.maggi@yale.edu

Ralph Ossa

University of Zurich

Department of Economics

Schoenberggasse 1

8001 Zuerich

Switzerland

ralph.ossa@econ.uzh.ch 


\section{Introduction}

After decades of trade liberalization, tariffs have reached historically low levels, so there is only limited scope for further tariff reductions. As a result, recent trade agreements largely revolve around non-tariff issues such as domestic regulations. For example, all the agreements signed by the US since the North American Free Trade Agreement (NAFTA) contain provisions on environmental and labor standards, and the same is true for most of the agreements signed by the EU, including the recent Comprehensive Economic and Trade Agreement (CETA) with Canada. ${ }^{1}$ Furthermore, many recent trade agreements have established regulatory cooperation councils that aim to coordinate national regulatory agencies on an ongoing basis. $^{2}$

Such deep agreements are very controversial, as evidenced for example by the massive protests against CETA and TTIP in Europe, which drew hundreds of thousands of people to the streets. While some opponents criticize any form of economic globalization, most object specifically to the deep integration elements. The overarching concern is that trade agreements may get hijacked by special interests, thus benefiting businesses at the expense of society. In particular, a common claim is that big corporations exert disproportionate influence on regulatory cooperation bodies, thereby undermining consumer safety and endangering the environment. A case in point was the public uproar against allowing the sale of chlorine-washed chicken in Europe, which had been banned earlier by the EU over food safety concerns.

An example of this kind of criticism is the following statement by the Institute for Agriculture and Trade Policy: "Regulatory cooperation activities most often take place behind closed doors, with a corporate-directed deregulatory agenda, and with minimal participation by civil society or stakeholders outside of the regulated industries ... Often, the goal of harmonization is to adopt international standards. These international standards are rarely the most protective, and they are developed with strong industry participation and sometimes, by private industry standardsetting organizations instead of by public agencies. As a result, there is strong pressure to harmonize standards down to the lowest common denominator..." (www.iatp.org/new-nafta-grp)

\footnotetext{
${ }^{1}$ See for example ustr.gov/issue-areas/environment/bilateral-and-regional-trade-agreements and ec.europa.eu/trade/policy/policy-making/sustainable-development.

${ }^{2}$ Some well-known regulatory cooperation councils are CETA's Regulatory Cooperation Forum, the Canada-US Regulatory Cooperation Council and the US-Mexico High Level Regulatory Cooperation Council, and a similar council is part of the proposed Transatlantic Trade and Investment Partnership (TTIP) between the EU and the US.
} 
These concerns are shared by some academic economists. For example, Rodrik (2018) argues informally that shallow integration is likely to enhance welfare because it empowers exporter lobbies and pits them against import-competing interests, but warns that deep integration may be bad for welfare because it empowers the "wrong" special interests. In this paper we take such concerns seriously and examine formally how global welfare is impacted by international regulatory agreements when such agreements are influenced by industrial lobbies. We next outline our modeling approach.

An important reference point of our analysis is the canonical "trade wars and trade talks" model of Grossman and Helpman (1995a), which examines noncooperative and cooperative trade policy choices by governments who are subject to lobbying pressures, and the subsequent work by Bagwell and Staiger (1999, 2001). A fundamental feature of the canonical model is that there is no political economy rationale for trade negotiations, in the sense that the only purpose of trade negotiations is to prevent countries from manipulating terms of trade.

Our approach differs from the canonical one in three main ways. First, we consider a continuum of small countries rather than two large countries. This allows us to put lobbying at the heart of trade negotiations, as small countries have no ability to manipulate terms of trade. ${ }^{3}$ Second, in order to examine how politically-motivated agreements affect global welfare, we distinguish between the governments" "positive" objectives and a "normative" criterion. Most existing models adopt the same government objective function to predict and evaluate trade policy choices, thus they cannot address the widespread concern that trade agreements benefit special interests at the expense of society. ${ }^{4}$ Third, and perhaps most importantly, we develop a new model of international regulatory cooperation. While simple and tractable, our model yields new insights regarding the welfare implications of deep agreements on domestic regulations, and how such implications differ across the areas of product standards and process regulations.

The simple overarching logic of our analysis can be described as follows. A key determinant of the welfare impacts of politically-pressured agreements is whether lobbies have more influence when policies are set unilaterally or when they are set by international negotiations;

\footnotetext{
${ }^{3}$ The feature that lobbying is key to the purpose of a trade agreement is present also in some domesticcommitment models of trade agreements, e.g. Maggi and Rodriguez-Clare (1998) and Mitra (2002). But these papers make very different points from the present paper, and they do not address deep agreements.

${ }^{4}$ Notable exceptions are Grossman and Helpman (1995b) and Ornelas (2005, 2008), who discuss whether politically-viable regional trade agreements are likely to cause more trade diversion or creation, and thus whether they are likely to increase or reduce welfare. But these papers do not examine deep integration.
} 
in the former case, international negotiations dilute the influence of lobbies, and agreements tend to be good for welfare; in the latter case, international negotiations intensify the influence of lobbies, so agreements may be bad for welfare. ${ }^{5}$ This depends crucially on whether the interests of a country's lobbies are aligned or in conflict with those of foreign countries' lobbies: in the former case, international negotiations induce "co-lobbying"; in the latter, they induce "countervailing lobbying." This in turn depends on the nature of the policy in question and on the underlying economic structure. Thus, for example, if a country loosens its product standards (in a non-discriminatory way), this benefits both domestic and foreign producers, so in this case there is co-lobbying, whereas loosening process standards benefits domestic producers while hurting foreign producers, so in this case there is countervailing lobbying. This basic intuition thus suggests that international cooperation may be less benign when negotiations focus on product standards than when they focus on process standards.

We now describe in more detail the main steps of our analysis, the key features of our model and our main results.

The starting point of our analysis is the benchmark case of shallow integration. In Section 2 we consider a competitive setting with many small countries where governments choose import tariffs. We find that shallow integration increases global welfare, provided only that it does not lead to large import subsidies. The reason is that trade negotiations empower exporter lobbies, which then act as counterweight to import-competing lobbies and thereby dilute the overall effect of special interests on trade policy. In the noncooperative equilibrium, exporter lobbies do not influence trade policy choices because a country's own tariffs can only help its import-competing producers. But this changes in the cooperative equilibrium, since the trading partners' tariffs become part of the bargain and a country's exporters benefit from increased market access elsewhere. ${ }^{6}$

We then turn to the main focus of our analysis, which is the political economy of regulatory cooperation and its welfare implications. To focus sharply on issues of deep integration, we consider a scenario where shallow integration has already occurred, so that tariffs have been removed, and we assume that domestic regulations are non-discriminatory, so they cannot

\footnotetext{
${ }^{5}$ The statements above are based on the notion that lobbying tends to be detrimental for welfare. In our setting this is always true if lobbies are sufficiently powerful, but may not be true if the power of lobbies is moderate. For example, if governments maximize welfare, it turns out that non-cooperative process standards are too tight because of an international externality, thus a moderate amount of lobbying pushes them closer to their efficient levels.

${ }^{6}$ As will become clear, a key ingredient of this result is that export subsidies are not available, an assumption that is descriptively realistic, given that export subsidies are essentially banned in the GATT-WTO.
} 
be used to create trade barriers. Also, to highlight more clearly the different implications of product standards versus process regulations, we initially examine two separate models, one that focuses only on product standards and one that focuses only on process regulations; we then put together these moving parts in an integrated model.

It is important to highlight that in reality both product standards and process standards are an important focus of international regulatory cooperation. Product standards have played an increasingly important role in deep integration agreements, the most recent examples being the CETA agreement and the proposed TTIP agreement. It is noteworthy that some of the most well-known controversies regarding deep integration (including the famous case of chlorine-washed chicken) have revolved around product standards. Also process standards, such as environmental regulations for factories and safety standards for workers, have been an important area of concern for many trade agreements in the last couple of decades, as mentioned at the outset. ${ }^{7}$

In Section 3 we focus on product standards, which are defined as restrictions on the characteristics of products sold in a given country. To provide a meaningful role for product standards, we introduce two new ingredients into our competitive many-country setting: first, consumption may generate a local negative externality; and second, products are vertically differentiated, with lower-quality products generating worse externalities (e.g. dirtier cars causing more pollution, or more hazardous toys causing worse health-cost externalities). ${ }^{8}$ Governments can use product standards to address the consumption externality, but they do so under political pressure from producer lobbies.

We find that agreements on product standards may decrease global welfare, and this is more likely to happen when lobbies are more powerful. What lies behind this result is the fact that the interests of producers world-wide are aligned, so international cooperation strengthens the overall influence of lobbies on the choice of standards. In particular, if a group of countries loosens their product standards, this benefits producers not only in those countries but also in the rest of the world, since it stimulates consumption and increases world prices. If lobbies are not very powerful, the welfare motivations for regulatory cooperation dominate political considerations, and thus the agreement enhances welfare, but if lobbies

\footnotetext{
${ }^{7}$ We note that not all labor standards can be included in our definition of process standards: for example, workplace safety and health standards do fall within our notion of process standards, but minimum wages do not.

${ }^{8}$ In this paper we focus on vertical standards. An examination of horizontal standards, such as compatibility standards motivated by the presence of network externalities, would require a very different setup. We briefly discuss horizontal standards in the Conclusion.
} 
are sufficiently powerful then international cooperation leads to excessive de-regulation and damages welfare.

These results may seem pessimistic, but they need to be interpreted in the right way. Our model abstracts from several potentially important features, such as the presence of large countries that can influence world prices, trans-boundary externalities from product standards, or possible domestic-commitment motives for an agreement. ${ }^{9}$ Each of these features would introduce an additional welfare rationale for international cooperation, and thus could lead to a positive welfare impact of the agreement even with strong lobbying pressures. But regardless of the sign of the welfare change, the more general prediction is that the influence of industrial lobbies tends to decrease the welfare gain, or increase the welfare loss, from an agreement on product standards. Thus the more general insight is not that agreements on product standards are necessarily bad for you, but rather, that the influence of industrial lobbies on these agreements is bad for you.

It is also important to keep in mind that many real-world trade agreements, including the GATT-WTO, are concerned with preventing the use of regulatory policies as a way to discriminate against foreign producers and thereby creating barriers to trade (this is the motivation behind the well-known "National Treatment" rule). We view this as part of "shallow" integration, and for this reason our model of deep integration does not consider the possibility of discriminatory standards. But our analysis of shallow integration in Section 2 suggests that, to the extent that an agreement tackles discriminatory standards, the influence of lobbies on the agreement is likely to be benign, because there should be counter-lobbying between import-competing producers and exporters.

In Section 4 we turn to a simple model of process regulations, which are defined as restrictions on production processes that take place on domestic soil. These include environmental standards imposed on factories and workplace safety standards. To introduce a role for process standards, we allow for local production externalities and suppose that production processes are vertically differentiated, with cheaper processes generating worse externalities. In analogy with the case of product standards, governments can use process regulations to address production externalities, but as we discuss next, the welfare implications of international agreements are very different for the two types of regulations.

\footnotetext{
${ }^{9}$ In this paper we suppose that lobbies influence international negotiations in a similar way as they influence policy choices in a non-cooperative scenario. But if lobbies have less influence on international agreements than on unilateral policies - which could be the case if governments seek international commitments to foreclose domestic political pressures, as for example in Maggi and Rodriguez-Clare (1998, 2007) - then intuitively international agreements would tend to have more benign welfare effects.
} 
Our model suggests that, in the case of process standards, lobbying pressures have a much more benign effect on the agreement than in the case of product standards. We find that agreements on process standards increase welfare if the power of lobbies is either sufficiently large or sufficiently small, and can decrease welfare only for an intermediate range of lobbying powers. A key ingredient of this result is that, as in the case of shallow agreements, the negotiation of a deep agreement triggers countervailing lobbying, but the cleavages that arise across the lobbying spectrum are different and more subtle. In the case of shallow agreements, there was a clear-cut cleavage between import-competing interests and export interests. In the case of agreements on process regulations, on the other hand, each lobby would like a loosening of its domestic regulations and a tightening of regulations in all foreign countries. This countervailing-lobbying effect implies that international negotiations tend to weaken the overall impact of lobbies on policy-making. But note one subtle aspect of the abovementioned result: in spite of the countervailing-lobbying effect, an agreement may decrease welfare for an intermediate range of lobbying powers. ${ }^{10}$

In Section 5 we consider an integrated model that allows for both types of regulations (product and process standards) and for both types of market failures (consumption and production externalities). We find that the equilibrium agreement changes product standards and process standards in opposite directions, and in particular, if the strength of lobbying is above a certain threshold then product standards are loosened and process standards are tightened, while the opposite is true if the strength of lobbying is below such threshold. As for the welfare effects of the agreement, we find that when lobbying pressures are strong, the agreement decreases welfare if the relative importance of production externalities versus consumption externalities is small - since in this case product standards play a dominant role relative to process standards - while it increases welfare in the opposite case. ${ }^{11}$

In the debate on the welfare effects of deep integration, the role of multinational en-

\footnotetext{
${ }^{10}$ We show that, if countries are sufficiently symmetric, there is always a non-empty intermediate range of lobbying powers such that the agreement decreases welfare.

${ }^{11}$ This is a good juncture to note that in reality there is a category of standards that does not fit neatly within our notions of product standards or process standards, and namely, restrictions on the sale of products that are produced with undesirable technologies or inputs. Examples of such standards are restrictions on products that are produced with child labor, or products with high carbon content. This type of standards may be motivated by cross-border externalities (e.g. global moral externalities in the case of child labor, or global pollution externalities in the case of carbon content), but note that they are less efficient than process standards imposed at the origin, so they are in a sense "third best" instruments. These standards are often proposed as unilateral policies to counter the unwillingness of producer countries to curb emissions from their factories or protect labor rights, and are typically not the focus of international agreements, thus we will abstract from them in this paper.
} 
terprises is sometimes mentioned as an additional reason for concern. It is natural to ask, therefore, whether or not the multinational nature of production tends to worsen the welfare impacts of deep integration. While our perfect-competition setting cannot speak to the role of multinational firms, since there is no meaningful notion of firms in such a setting, the model can be easily extended to allow for foreign ownership of production factors. In Section 6 we examine how the presence of international ownership linkages affects our welfare results. We find that, compared with a world where factor ownership is purely domestic, the presence of foreign ownership tends to reduce the welfare gains (or increase the welfare losses) from deep integration, at least if lobbies are sufficiently strong. This is the consequence of three observations. First, foreign ownership pushes non-cooperative process standards closer to their efficient levels, since it dilutes their impact on domestic producers. Second, it has no effect on non-cooperative product standards, because an individual country's choice of product standards does not affect domestic producers, as highlighted above. And third, it has little effect on cooperative policies, because in the cooperative scenario only the aggregate world factor supplies matter, not the way their ownership is distributed across countries.

Before plunging into the analysis, we discuss briefly the related literature.

There is a sizable literature on shallow agreements in the presence of lobbying pressures. As mentioned above, two key examples of the "canonical" model of shallow integration are Grossman and Helpman (1995a) and Bagwell and Staiger (1999, 2001). It is worth noting that in these models governments can use export subsidies, and as a consequence exporter lobbies do not play a key role in shaping trade agreements. But there are also several models within this broad family where export subsidies are restricted, and as a consequence exporter lobbies play a key role in the shaping of trade agreements, just as in our benchmark model of shallow integration: see for example Grossman and Helpman (1995b), Levy (1999), Ornelas (2005, 2008), Bagwell and Staiger (2011), Ludema and Mayda (2016), Nicita et al (2018) and Lazarevski (2018). We note that most papers in this family do not examine the welfare implications of politically-motivated trade agreements, with the only exceptions of the regional-agreement models of Grossman and Helpman (1995b) and Ornelas (2005, 2008).

The literature on the political economy of deep integration is very thin, and we are not aware of any model that examines the welfare impacts of politically-pressured deep agreements. Nevertheless there are papers in the literature that have points of contact with our model of regulatory cooperation. For example, a recent paper by Grossman et al. (2019) considers the optimal design of international agreements in a setting where governments 
can choose product standards as well as standard taxes. The questions they address are very different from ours, however. Among other things, they focus on the tradeoff between harmonization and regulatory diversity in a setting of horizontal standards and fixed costs of standards compliance, an issue that is not a focus of our paper. ${ }^{12}$

The paper proceeds as follows. Section 2 focuses on the benchmark case of shallow integration. Sections 3 and 4 consider deep agreements respectively on product standards and process standards. Section 5 presents the integrated model with both types of regulations. Section 6 extends the model to allow for international ownership linkages. Section 7 concludes.

\section{Benchmark: Shallow Integration}

We start by focusing on the benchmark case of shallow integration. The economic environment we consider differs from the canonical terms-of-trade models (e.g. Grossman and Helpman, 1995a) in one main respect: we assume a continuum of small countries rather than two large countries, in order to focus more sharply on the role of lobbying in the shaping of trade agreements.

\subsection{Setup}

We consider a perfectly competitive world with a continuum of countries and $\mathcal{G}+1$ goods. Good 0 is the numeraire. Here and throughout, we normalize the mass of countries to one.

In each country $i$ there is a unit mass of citizens with the following quasi-linear preferences

$$
U_{i}=c_{i 0}+\sum_{g \in \mathcal{G}} u_{i g}\left(c_{i g}\right)
$$

where $c_{i 0}$ denotes country $i$ 's consumption of the numeraire good, $c_{i g}$ denotes country $i$ 's consumption of good $g$, and $u_{i g}(\cdot)$ satisfies the usual properties $u_{i g}^{\prime}(\cdot)>0$ and $u_{i g}^{\prime \prime}(\cdot)<0$. Utility maximization implies $p_{i g}=u_{i g}^{\prime}\left(c_{i g}\right)$, which can be inverted to yield the demand function $c_{i g}=d_{i g}\left(p_{i g}\right)$, where $p_{i g}$ is the price of good $g$ in country $i$. The indirect utility of country $i$ with income $Y_{i}$ is then given by $V_{i}=Y_{i}+\sum_{g \in \mathcal{G}} S_{i g}\left(p_{i g}\right)$, where $S_{i g}\left(p_{i g}\right) \equiv$ $u_{i g}\left(d_{i g}\left(p_{i g}\right)\right)-p_{i g} d_{i g}\left(p_{i g}\right)$ is consumer surplus.

\footnotetext{
${ }^{12} \mathrm{~A}$ pioneering contribution to this literature is Costinot (2008), who compares a GATT-style nationaltreatment approach with an EU-style mutual-recognition approach, arguing that the former tends be more effective in the case of vertical standards and the latter may be more appropriate for horizontal standards. See also a recent paper by Mei (2019), who conducts a quantitative analysis of the national-treatment approach as compared with a full international negotiation of standards.
} 
The numeraire good is produced one-for-one from labor. We assume that in each country there is positive production of the numeraire good in equilibrium, so the wage is equal to one everywhere. Each non-numeraire good is produced from labor and a sector-specific input whose returns in country $i$ we denote by $\pi_{i g}$. Hotelling's lemma implies that $y_{i g}\left(p_{i g}\right)=$ $\pi_{i g}^{\prime}\left(p_{i g}\right)$, where $y_{i g}$ is country $i$ 's supply of $\operatorname{good} g$.

Countries can impose specific tariffs $\tau_{i g}$ on imported non-numeraire goods and do not have access to export policies. ${ }^{13}$ Also, in line with most political-economy models of trade policy (including the Grossman-Helpman model), we assume away production subsidies. There are no trade costs other than the tariffs governments impose. Finally, we assume that the numeraire good is freely traded. ${ }^{14}$

We denote the subset of countries which import good $g$ by $\mathcal{M}_{g}$ and the subset of countries which export good $g$ by $\mathcal{X}_{g}$. Since tariffs drive a wedge between local prices and world prices and there are no export policy instruments, local prices satisfy $p_{i g}=p_{g}+\tau_{i g}$ for all $i \in \mathcal{M}_{g}$ and $p_{i g}=p_{g}$ for all $i \in \mathcal{X}_{g}$, where $p_{g}$ is the world price of good $g$.

World prices are pinned down by world market clearing. Letting $m_{i g}\left(p_{i g}\right)=d_{i g}\left(p_{i g}\right)-$ $y_{i g}\left(p_{i g}\right)$ and $x_{i g}\left(p_{i g}\right)=y_{i g}\left(p_{i g}\right)-d_{i g}\left(p_{i g}\right)$, we can express the world market clearing conditions as

$$
\int_{i \in \mathcal{M}_{g}} m_{i g}\left(p_{g}+\tau_{i g}\right)=\int_{i \in \mathcal{X}_{g}} x_{i g}\left(p_{g}\right) .
$$

Total income in country $i$ consists of labor income, which is equal to one, producer surplus $\sum_{g \in \mathcal{G}} \pi_{i g}$, and tariff revenue $\sum_{g \in \mathcal{G}} R_{i g}$, thus indirect utility can be rewritten as $V_{i}=$ $1+\sum_{g \in \mathcal{G}}\left(\pi_{i g}+S_{i g}+R_{i g}\right)$. We can abstract from the first term in $V_{i}$ and simply define

\footnotetext{
${ }^{13}$ Export subsidies were banned long ago by GATT, so the model can be thought of as applying to tariff negotiations that have occurred after the export subsidy ban. While the assumption that export subsidies are unavailable seems descriptively realistic, the export subsidy ban is hard to explain based on standard trade models (see Maggi, 2014, for a survey of the relevant literature), but this is not a focus of our paper, and we just take this as a fact of life. And as discussed in the Introduction, we share the no-export-subsidy assumption with a large number of mainstream models of trade agreements. We also note that in our model there is no reason for a government to use export taxes, so assuming away export taxes is not restrictive in our setting.

${ }^{14}$ The assumption that the numeraire good is untaxed would in itself be without loss of generality, but in conjunction with the no-export-subsidy assumption it is not innocuous (we owe this observation to Ivan Werning). If we allowed for trade taxes on all goods, the effects of export subsidies could be replicated by choosing appropriate import and export taxes. We have in mind a slightly richer (and we believe more realistic) model that would not be subject to this issue and is likely to deliver similar insights as our current model, and in particular, a model where (at least) one good is not tradable. In such a setting, the noexport-subsidy restriction in general would be binding. However, non-traded goods would introduce generalequilibrium effects that are currently absent, so some qualifications to our results might arise.
} 
welfare as the familiar sum of producer surplus, consumer surplus, and tariff revenue:

$$
W_{i}=\sum_{g \in \mathcal{G}} W_{i g}=\sum_{g \in \mathcal{G}}\left(\pi_{i g}+S_{i g}+R_{i g}\right)
$$

Governments are subject to lobbying pressures, so their objective function does not coincide with welfare. In the same spirit as Grossman and Helpman (1994, 1995a), we assume lobbies represent the groups of specific-factor owners, and we capture the influence that lobbies have on the government by assuming that government $i$ attaches extra weights $\gamma_{i g} \geq 0$ to the producer surplus in the various sectors. ${ }^{15}$ Thus government $i$ maximizes:

$$
\Omega_{i}=\sum_{g \in \mathcal{G}} \Omega_{i g}=\sum_{g \in \mathcal{G}}\left[\left(1+\gamma_{i g}\right) \pi_{i g}+S_{i g}+R_{i g}\right]
$$

A remark is in order on the difference between our "positive" government objective (4) and our "normative" criterion (3). We have adopted a utilitarian definition of welfare (just as in the Grossman-Helpman model) because it is the simplest and most natural one in this transferrable-utility environment, but we have in mind a broader interpretation: if we assigned different Pareto weights to different groups in our welfare criterion, our government objective would reflect these welfare weights plus the "bias" $\gamma_{i g}$ introduced by lobbying. What really matters for our results is that producer groups get more weight in the government objective than in the welfare criterion.

Next we compare the noncooperative equilibrium with the cooperative policy regime.

\subsection{Noncooperative equilibrium}

In the noncooperative equilibrium, each importing country unilaterally sets tariffs to maximize $\Omega_{i}=\sum_{g \in \mathcal{G}} \Omega_{i g}$, taking world prices and other countries' tariffs as given. Since each country is small relative to the rest of the world, it takes world prices as given. This problem is separable across goods, so we can focus on a single good $g$ :

$$
\max _{\tau_{i g}} \Omega_{i g}=\left(1+\gamma_{i g}\right) \pi_{i g}\left(p_{g}+\tau_{i g}\right)+S_{i g}\left(p_{g}+\tau_{i g}\right)+\tau_{i g} m_{i g}\left(p_{g}+\tau_{i g}\right), \quad i \in \mathcal{M}_{g}
$$

\footnotetext{
${ }^{15}$ This formulation of a government's objective is similar as in Baldwin (1987), and can be viewed as a reduced-form version of the government objectives in Grossman and Helpman (1994). In the latter model, $\gamma_{i g}=\frac{I_{i g}-\alpha_{i}^{L}}{a_{i}-\alpha_{i}^{L}}$, where $I_{i g}$ is a dummy that is equal to one if industry $i$ is politically organized, $\alpha_{i}^{L}$ is the share of the population represented by some lobby, and $a_{i}$ is government $i$ 's valuation of welfare relative to campaign contributions. Also note that this model of lobbying implicitly assumes that labor-owners or consumers at large are not able to get politically organized, since these are large and dispersed economy-wide groups, so it is more difficult for them to overcome collective action problems.
} 
We assume that $\Omega_{i g}$ is concave in $\tau_{i g}$ for all $i$, so we can rely on first-order conditions. It is direct to verify that the noncooperative tariffs and world price for good $g$ must satisfy:

$$
\begin{gathered}
\tau_{i g}=\frac{\gamma_{i g} y_{i g}\left(p_{g}+\tau_{i g}\right)}{-m_{i g}^{\prime}\left(p_{g}+\tau_{i g}\right)}, \quad i \in \mathcal{M}_{g} \text { and } \\
\int_{i \in \mathcal{M}_{g}} m_{i g}\left(p_{g}+\tau_{i g}\right)=\int_{i \in \mathcal{X}_{g}} x_{i g}\left(p_{g}\right)
\end{gathered}
$$

We assume that the noncooperative equilibrium exists and is unique, meaning that there exists a unique solution to equations (5) and (6).

Notice that noncooperative tariffs are zero if $\gamma_{i g}=0$, so lobbying is the only reason why governments deviate from free trade. And importantly, exporter interests are not taken into account in the noncooperative tariffs, since countries cannot unilaterally affect domestic prices in their exporting industries.

\subsection{Cooperative tariffs}

In the cooperative regime, countries set tariffs to maximize their joint payoff $\Omega \equiv \int_{i} \Omega_{i}=$ $\sum_{g \in \mathcal{G}} \int_{i} \Omega_{i g}$ taking into account the impact of tariffs on world prices. ${ }^{16}$ This problem is again separable across industries, so it suffices to maximize $\Omega_{g}$ :

$$
\begin{gathered}
\max _{\left\{\tau_{i g}\right\}_{i \in \mathcal{M}_{g}}, p_{g}} \Omega_{g}=\int_{i}\left[\left(1+\gamma_{i g}\right) \pi_{i g}\left(p_{g}+\tau_{i g}\right)+S_{i g}\left(p_{g}+\tau_{i g}\right)+\tau_{i g} m_{i g}\left(p_{g}+\tau_{i g}\right)\right] \\
\text { s.t. } \int_{i \in \mathcal{M}_{g}} m_{i g}\left(p_{g}+\tau_{i g}\right)=\int_{i \in \mathcal{X}_{g}} x_{i g}\left(p_{g}\right),
\end{gathered}
$$

where we keep in mind that $\tau_{i g}=0$ for $i \in \mathcal{X}_{g}$ in the expression above. In order to rely on a first-order-condition approach, we assume that $\Omega_{g}\left(\boldsymbol{\tau}_{g}, p_{g}\left(\boldsymbol{\tau}_{g}\right)\right)$ is concave in the tariff vector $\boldsymbol{\tau}_{g}$, where $p_{g}\left(\boldsymbol{\tau}_{g}\right)$ denotes the market-clearing price as a function of the tariffs (it is easy to show that this function is well-defined).

This problem can be solved with a standard Lagrangian approach. It is not hard to show that the cooperative tariffs and world price for good $g$ satisfy:

$$
\begin{gathered}
\tau_{i g}=\frac{\gamma_{i g} y_{i g}\left(p_{g}+\tau_{i g}\right)}{-m_{i g}^{\prime}\left(p_{g}+\tau_{i g}\right)}-\frac{\int_{i \in \mathcal{X}_{g}} \gamma_{i g} y_{i g}\left(p_{g}+\tau_{i g}\right)}{\int_{i \in \mathcal{X}_{g}} x_{i g}^{\prime}\left(p_{g}\right)}, \quad i \in \mathcal{M}_{g} \\
\int_{i \in \mathcal{M}_{g}} m_{i g}\left(p_{g}+\tau_{i g}\right)=\int_{i \in \mathcal{X}_{g}} x_{i g}\left(p_{g}\right)
\end{gathered}
$$

\footnotetext{
${ }^{16}$ We are implicitly assuming that countries have access to international transfers (in terms of the numeraire good). Given that governments have many ways to compensate each other in the context of trade negotiations, this assumption seems reasonable, but in any case it is not essential to our main qualitative results.
} 
We assume that a solution to the above system of equations exists (note that uniqueness is guaranteed by concavity of the objective function). The key difference between the noncooperative tariffs and the cooperative tariffs is the presence of the term $\frac{\int_{i \in \mathcal{X}_{g}} \gamma_{i g} y_{i g}}{\int_{i \in \mathcal{X}_{g}} x_{i g}^{\prime}}>0$ in equation (7). Notice that the numerator of this term captures the joint political power of exporters, since it integrates over all countries that are exporters of good $g$. This captures the idea that exporter interests are taken into account in the cooperative equilibrium, since countries can jointly increase world prices through tariff cuts.

\subsection{What does the agreement do?}

As we establish formally in the Appendix, under a mild regularity condition the trade agreement reduces all tariffs relative to the noncooperative equilibrium. Notice that this does not follow immediately from a comparison of equations (5) and (7), since they are evaluated at different world prices. ${ }^{17}$

The broad intuition for this result is that noncooperative tariffs reflect only the interests of import-competing producers, while cooperative tariffs also reflect the interests of exporters, who benefit from trade liberalization. But we can gain a deeper intuition for the tariff formula (7) by considering the international externalities exerted by tariffs through the world price. Suppose a positive measure of importing countries decreases their tariffs. This pushes up the world price by increasing import demand. How does this affect all other countries in the aggregate? Differentiating the joint payoff $\Omega_{g}$ with respect to the world price and evaluating at the noncooperative tariffs, we find:

$$
\left.\frac{\partial \Omega_{g}}{\partial p_{g}}\right|_{N E}=-\int_{i \in \mathcal{M}_{g}} m_{i g}+\int_{i \in \mathcal{X}_{g}}\left(\gamma_{i g} y_{i g}+x_{i g}\right)=\int_{i \in \mathcal{X}_{g}} \gamma_{i g} y_{i g}
$$

The first term indicates that the externality of a decrease in tariffs on other importers is negative, since an increase in the world price is a deterioration of all importers' terms-oftrade. The second term shows that the externality on exporters is positive, for two reasons: it increases the political surplus for all exporters, and it improves their terms-of-trade. But

\footnotetext{
${ }^{17}$ The regularity condition we need is a slight strengthening of the assumptions made above that there exists a unique noncooperative equilibrium and a unique solution to the first-order conditions of the cooperative problem. In particular, we assume that there exists a unique solution to the system of equations given by $\tau_{i g}=\frac{\gamma_{i g} y_{i g}\left(p_{g}+\tau_{i g}\right)}{-m_{i g}^{\prime}\left(p_{g}+\tau_{i g}\right)}-\kappa_{g}$ and $\int_{i \in \mathcal{M}_{g}} m_{i g}\left(p_{g}+\tau_{i g}\right)=\int_{i \in \mathcal{X}_{g}} x_{i g}\left(p_{g}\right)$ for all $\kappa_{g} \in\left[0, \lambda_{g}\right]$, where $\lambda_{g}$ is the Lagrange multiplier of the cooperative problem. The assumptions already made above imply that this is true for $\kappa_{g}=0$ and for $\kappa_{g}=\lambda_{g}$, so here we are extending the condition to intermediate values of $\kappa_{g}$. This assumption allows us to define a path that connects the noncooperative solution with the cooperative solution in the price-tariffs space, and evaluate how welfare changes along this path.
} 
the importers' aggregate terms-of-trade loss equals the exporters' aggregate terms-of-trade gain, so only the political externality $\int_{i \in \mathcal{X}_{g}} \gamma_{i g} y_{i g}$ remains. It is this externality that the trade agreement internalizes, as reflected in formula (7). Note that the net aggregate world-price externality does not include the political gain for importers $\left(\int_{i \in \mathcal{M}_{g}} \gamma_{i g} y_{i g}\right)$, and the reason is that importers use tariffs optimally to benefit their domestic producers, whereas exporters lack policy instruments to do so.

While in our setting the purpose of a trade agreement is to deal with terms-of-trade externalities, there is a fundamental difference between the motives behind trade agreements in our model and in the standard terms-of-trade theory. In our model, the purpose of a trade agreement is not to prevent individual countries from manipulating terms-of-trade, because individual countries use tariffs only for political reasons, not to manipulate terms-of-trade. Rather, a trade agreement is motivated by lobbying pressures from exporters, given that export subsidies are restricted. It is useful to note that, if export subsidies were available, the externality (9) would be zero and hence noncooperative tariffs would be efficient, so there would be no scope for a trade agreement. And it is also apparent from (9) that there would be no need for an agreement if governments were welfare-maximizers.

We record the result above in the following proposition. The proofs of this and all other propositions are in the Appendix.

Proposition 1 The equilibrium trade agreement lowers all import tariffs relative to noncooperative levels, provided the aggregate political power of exporters is strictly positive.

This result captures an often-heard "story" about the success of GATT/WTO negotiations that is quite different from the standard terms-of-trade theory: tariffs fell because the GATT/WTO changed the political calculus of policy makers, and lobbying pressures from exporter groups counter-balanced the pressures from import-competing groups, thus diluting the overall effect of lobbying on trade policy. The standard terms-of-trade story, on the other hand, is that tariffs fell because the agreement removed the individual countries' incentives to manipulate terms of trade.

\subsection{Is it good for you?}

Given that all tariffs fall as a result of the trade agreement, one might conjecture that it has positive welfare effects. This is not immediately obvious because we are allowing countries to be asymmetric in a number of dimensions, and we know from second-best theory that partial 
reductions of distortions (wedges) do not necessarily increase welfare. But we do confirm this conjecture, subject to the condition that the agreement not entail large import subsidies. We record this point with:

Proposition 2 The equilibrium trade agreement improves global welfare relative to the noncooperative equilibrium, provided the agreement does not entail large import subsidies.

This result suggests that we should not be excessively worried about the influence that producer lobbies have on shallow trade agreements. Intuitively, tariff negotiations trigger counter-lobbying between import-competing groups and exporting groups, hence diluting the overall effect of lobbying on trade policy relative to the non-cooperative equilibrium.

We can now turn to the main focus of our paper, that is the welfare implications of deep agreements.

\section{Deep integration: product standards}

In this section we start addressing the main question of our paper: what are the welfare effects of international regulatory cooperation when international negotiations are influenced by industrial lobbies?

As will soon become clear, the welfare implications of international regulatory agreements can be quite different depending on whether the agreement focuses on product standards or on process regulations. To put these contrasting implications in sharp relief, we initially examine two separate models, one that focuses only on product standards and one that focuses only on process regulations; we will later consider an integrated model that allows for both types of regulations. Also, to focus sharply on the effects of deep integration, we consider a scenario where shallow integration has already occurred, so that tariffs have been removed, and we assume that standards satisfy national treatment (i.e. they are non-discriminatory).

We start by focusing on product standards, which are defined as restrictions on the characteristics of products sold in a given country. Examples include emissions standards for automobiles, safety standards for children's toys, or health standards for meat products. As mentioned in the Introduction, product standards have played a key role in a number of recent international negotiations, and have been at the center of some of the most well-known controversies regarding deep agreements. 


\subsection{Setup}

We modify the economic structure of section 2 in two ways. First, to introduce a role for product standards, we now assume that each good comes in a continuum of varieties, indexed by their "dirtiness" $e_{g} \in[0, \infty)$. Cleaner goods are more costly: in particular, producers have to incur an abatement cost $1 / e_{g}$ in terms of the outside good in order to produce variety $e_{g}{ }^{18}$ We assume that varieties are indistinguishable in the eyes of consumers.

Second, to provide a potential welfare rationale for product standards we allow for local consumption externalities. For concreteness we will focus on environmental externalities. For example, $e_{g}$ may index the amount of emissions generated by a car. But alternative interpretations are also possible, for example health-care externalities caused by the consumption of unsafe products.

Since each consumer is atomistic (and thus ignores the effects of her individual consumption on aggregate consumption) and regards all varieties as perfect substitutes, the demand for good $g$ in country $i$ depends only on the consumer price $p_{i g}^{c}$, and will be denoted $d_{i g}\left(p_{i g}^{c}\right)$.

As will become clear below, in each country $i$ there will be a single variety of good $g$ that is consumed in equilibrium, say variety $e_{i g}$. Assuming that consuming one unit of variety $e_{i g}$ generates $e_{i g}$ units of pollution, the total amount of pollution is then $e_{i g} d_{i g}\left(p_{i g}^{c}\right)$. In the case of cars, this would be the total amount of emissions from cars in country $i$. The disutility caused by a unit of pollution for the representative consumer in country $i$ is assumed to be constant and denoted by $a_{i g}$, so the local externality associated with consumption of variety $e_{i g}$ can be written as $-a_{i g} e_{i g} d_{i g}\left(p_{i g}^{c}\right)$. The parameter $a_{i g}$ can be interpreted as an environmentalpreference parameter, capturing how strongly country $i$ feels against pollution. ${ }^{19}$

Each government $i$ chooses emission standards $\left\{e_{i g}\right\}_{g \in \mathcal{G}}$ for products sold in its own market. These can be interpreted as emission caps, because in this setting a cap is always binding, due to the fact that producing cleaner products is more costly and varieties are indistinguishable in the eyes of consumers.

As mentioned above, we focus on a scenario where shallow integration has already occurred, so trade taxes have been removed, and we continue to assume away production subsidies. ${ }^{20}$ We thus assume that product standards are the only policies available to gov-

\footnotetext{
${ }^{18}$ Notice that this implies convex abatement costs. Our results extend to a more general convex abatement cost function.

${ }^{19}$ We are implicitly assuming that the disutility from pollution enters utility in a separable way. More specifically, we are assuming a direct utility function of the form $U_{i}=c_{i 0}+\sum_{g \in \mathcal{G}}\left[u_{i g}\left(c_{i g}\right)-a_{i g} e_{i g} C_{i g}\right]$, where $c_{i g}$ and $C_{i g}$ denote respectively individual and aggregate consumption of variety $e_{i g}$.

${ }^{20}$ If production subsidies were available, producer lobbies would focus their efforts on production subsidies,
} 
ernments.

Having laid out our assumptions, the first observation concerns the price wedges created by product standards. Since there are no trade costs, producer arbitrage ensures that producers get the same price net of abatement costs in any market where they sell. And since each individual country is small, its choice of standards cannot affect the net price received by its producers. Letting $p_{g}$ denote the producer price net of abatement costs, the price faced by consumers in country $i$ is therefore $p_{i g}^{c}=p_{g}+\frac{1}{e_{i g}}$. We will often refer to the net producer price $p_{g}$ as the "world" price. ${ }^{21}$ Thus, if an individual country $i$ chooses to tighten its standards, the associated cost falls entirely on its consumers. ${ }^{22}$ This feature will play a key role for our results on product standards, and as will become clear, it differs crucially from the case of process standards, because in the latter case the burden of standards will fall on local producers rather than on local consumers.

Using the above observations, we can write country $i$ 's welfare as:

$$
W_{i}=\sum_{g \in \mathcal{G}}\left[\pi_{i g}\left(p_{g}\right)+S_{i g}\left(p_{g}+\frac{1}{e_{i g}}\right)-a_{i g} e_{i g} d_{i g}\left(p_{g}+\frac{1}{e_{i g}}\right)\right],
$$

and as in the previous section we assume that government $i$ 's objective is given by

$$
\Omega_{i}=W_{i}+\sum_{g \in \mathcal{G}} \gamma_{i g} \pi_{i g}
$$

Note that a product standard is a second-best policy, because given the variety $e_{i g}$ selected by the government, consumers do not internalize the consumption externality. One way to implement the first best is to combine a product standard with a consumption tax. At the end of this section we will argue that, if both instruments were available, our conclusions would get strengthened.

not on regulations, since the former are more efficient redistribution tools, thus it would be hard to explain the influence of lobbies on regulations, just as it would be hard to explain the influence of lobbies on trade policies. While assuming away production subsidies is in line with most of the existing political-economy literature, it would certainly be desirable to endogenize such restriction within the context of our model, since this could conceivably affect our qualitative results. One possible approach for example would be to adopt the Drazen-Limao (2008) model, where a government may prefer to commit not to use more efficient redistribution tools in order to strengthen its bargaining position when dealing with domestic lobbies.

${ }^{21}$ This is the net price that producers of each country can get if they sell anywhere in the world, and also the price that consumers of a country would pay if that country imposed no standard at all $\left(e_{i g}=\infty\right)$.

${ }^{22}$ Note that, in our setting with constant returns, there is no cost in producing different varieties for different markets. In the Conclusion we will discuss how results might change if there are fixed costs of adapting a product to a country's local standard. 


\subsection{Noncooperative product standards}

In the noncooperative scenario, each government $i$ solves:

$$
\max _{e_{i g}} \Omega_{i g}=\left(1+\gamma_{i g}\right) \pi_{i g}\left(p_{g}\right)+S_{i g}\left(p_{g}+\frac{1}{e_{i g}}\right)-a_{i g} e_{i g} d_{i g}\left(p_{g}+\frac{1}{e_{i g}}\right) .
$$

We assume that $\Omega_{i g}$ is concave in $e_{i g}$, so we can rely on first-order conditions. Straightforward algebra reveals that the first-order conditions imply:

$$
e_{i g}=-\frac{\sigma_{i g}}{2}+\sqrt{\left(\frac{\sigma_{i g}}{2}\right)^{2}+\frac{1}{a_{i g}}} \text { for all } i
$$

where $\sigma_{i g} \equiv-\frac{d_{i g}^{\prime}}{d_{i g}}>0$ denotes the demand semi-elasticity. The market clearing condition can be written as:

$$
\int_{i} y_{i g}\left(p_{g}\right)=\int_{i} d_{i g}\left(p_{g}+\frac{1}{e_{i g}}\right) .
$$

The noncooperative equilibrium product standards and world price for good $g$ solve equations (10) and (11). We assume that such solution exists and is unique, and denote it $\left(\left\{e_{i g}^{N}\right\}, p_{g}^{N}\right) \cdot{ }^{23}$

Notice that, if $\sigma_{i g}$ is held constant, increasing the strength of the externality $a_{i g}$ leads to tighter noncooperative standards, as one would expect. Also note that the strength of lobbies does not affect noncooperative product standards, since the political parameters $\gamma_{i g}$ do not enter the above system of equations. The reason is that a small country cannot affect the net producer price $p_{g}$ with a product standard, so this instrument cannot be used to help domestic producers. This feature depends on our assumptions of small countries and zero trade costs, but as will become clear, it does not drive our qualitative insights.

\subsection{Cooperative product standards}

When acting cooperatively, governments maximize their joint payoff taking into account the effect of product standards on world prices. Thus cooperative product standards solve:

$$
\max _{\left\{e_{i g}\right\}, p_{g}} \Omega_{g}=\int_{i}\left[\left(1+\gamma_{i g}\right) \pi_{i g}\left(p_{g}\right)+S_{i g}\left(p_{g}+\frac{1}{e_{i g}}\right)-a_{i g} e_{i g} d_{i g}\left(p_{g}+\frac{1}{e_{i g}}\right)\right]
$$

\footnotetext{
${ }^{23}$ Note that existence and uniqueness is guaranteed if $\sigma_{i g}$ is constant, but not if $\sigma_{i g}$ varies with the consumer price.
} 


$$
\text { s.t. } \int_{i} y_{i g}\left(p_{g}\right)=\int_{i} d_{i g}\left(p_{g}+\frac{1}{e_{i g}}\right) .
$$

To rely on first-order conditions, we assume that $\Omega_{g}\left(\mathbf{e}_{g}, p_{g}\left(\mathbf{e}_{g}\right)\right)$ is concave in the vector of standards $\mathbf{e}_{g}$, where $p_{g}\left(\mathbf{e}_{g}\right)$ denotes the market-clearing price as a function of the standards. We require concavity of $\Omega_{g}$ for any set of political parameters $\gamma_{i g} \geq 0$, so this assumption implies that global welfare is concave in $\mathbf{e}_{g} \cdot{ }^{24}$

Letting $\lambda_{g}$ denote the Lagrange multiplier, it is direct to verify that the cooperative standards and world price for good $g$ satisfy the following conditions (we suppress the arguments of all functions for simplicity):

$$
\begin{gathered}
e_{i g}=-\frac{\sigma_{i g}}{2}+\sqrt{\left(\frac{\sigma_{i g}}{2}\right)^{2}+\frac{1}{a_{i g}}\left(1+\lambda_{g} \sigma_{i g}\right)} \text { for all } i \\
\lambda_{g}=\frac{\int_{i}\left(\gamma_{i g} y_{i g}+a_{i g} e_{i g} \sigma_{i g} d_{i g}\right)}{\int_{i}\left(\varepsilon_{i g} y_{i g}+\sigma_{i g} d_{i g}\right)}>0 \\
\int_{i} y_{i g}=\int_{i} d_{i g},
\end{gathered}
$$

where $\varepsilon_{i g} \equiv \frac{y_{i g}^{\prime}}{y_{i g}}>0$ denotes the semi-elasticity of supply. We assume that the above system of equations has a solution (which is then unique given our concavity assumption), and denote it $\left(\left\{e_{i g}^{A}\right\}, p_{g}^{A}, \lambda_{g}^{A}\right)$.

The main difference between the noncooperative and cooperative product standards is the presence of the multiplier $\lambda_{g}$ in equation (13). Note that $\lambda_{g}>0$ even if $\gamma_{i g}=0$, thus the agreement changes standards for both political and environmental reasons, a finding that we explore more thoroughly below. For now, just notice that all producers have a common interest in loosening product standards, since they all benefit from the resulting increase in the world price.

Also note that, since the demand semi-elasticities $\sigma_{i g}$ in general depend on prices, and the agreement changes prices, we cannot immediately infer from equations (10) and (13) whether the agreement loosens or tightens standards. ${ }^{25}$ We investigate this question next.

\footnotetext{
${ }^{24}$ Since the producer surplus $\pi_{i g}$ is convex in $p_{g}$, the reader might wonder if the assumption that $\Omega_{g}\left(\mathbf{e}_{g}, p_{g}\left(\mathbf{e}_{g}\right)\right)$ is concave can hold for large values of the political parameters $\gamma_{i g}$. The answer is yes. Consider for simplicity the case of symmetric countries (so we can omit the $i$ subscript). The key is to note that, as $e_{g} \rightarrow \infty$, the market price $p_{g}$ converges to the no-regulation price, and as a consequence $\pi_{g}$ flattens out. This implies that $\pi_{g}\left(p_{g}\left(e_{g}\right)\right)$ is concave in $e_{g}$ for $e_{g}$ large enough. Moreover, the optimal $e_{g}$ is increasing in $\gamma_{g}$, so when $\gamma_{g}$ is larger $\pi_{g}\left(p_{g}\left(e_{g}\right)\right)$ is more likely to be concave in $e_{g}$.

${ }^{25}$ To simplify some of the proofs, we make the technical assumptions that the semi-elasticities $\sigma_{i g}$ and $\varepsilon_{i g}$ are bounded above and bounded away from zero.
} 


\subsection{What does the agreement do?}

We now examine how the agreement changes product standards relative to the noncooperative equilibrium. Here we take a heuristic approach, relegating the formal arguments to the appendix.

We start with a local argument. Let us consider the international externalities caused by a change in product standards starting from the noncooperative equilibrium. Suppose a positive measure of countries loosens their standards. This pushes up the world price by boosting demand. ${ }^{26}$ How does this affect the joint payoff of all governments? Differentiating the joint government payoff $\Omega_{g}$ with respect to $p_{g}$ and plugging in the expression for noncooperative standards (10), we obtain:

$$
\left.\frac{\partial \Omega_{g}}{\partial p_{g}}\right|_{N E}=\int_{i}\left(\gamma_{i g} y_{i g}+a_{i g} e_{i g}^{N} \sigma_{i g} d_{i g}\right)>0
$$

The first term is positive and captures the beneficial effect of an increase in the world price for producers worldwide. This is similar to the political world-price externality discussed in the context of shallow integration, with the important difference that now all producers benefit, not just exporters. The second term is also positive and is due to the fact that an increase in the world price reduces consumption and thereby mitigates the local environmental externality in all countries. Thus the aggregate international externality from loosening product standards is positive for two reasons, a political one and an environmental one.

Having argued that, when starting from the noncooperative equilibrium, the aggregate international externality from loosening product standards is positive, one can then show that the "local agreement" entails increasing $e_{i g}$ for all countries, where the local agreement is defined as the local change in product standards that achieves the steepest rate of improvement in the objective starting from noncooperative standards. Intuitively, if we marginally loosen standards in a group of countries starting from noncooperative levels, this causes a first-order positive externality on the other countries (as we argued above), while the loss for the countries loosening their standards is second-order, because they were starting from unilaterally-optimal levels, therefore the joint payoff $\Omega_{g}$ increases.

We can show that this local result holds globally if certain sufficient conditions are satisfied (in addition to concavity of $\Omega_{g}\left(\mathbf{e}_{g}, p_{g}\left(\mathbf{e}_{g}\right)\right)$ ), and in particular, if countries are sufficiently close

\footnotetext{
${ }^{26}$ To see this, differentiate the market clearing condition to get $d p_{g}=\frac{-\int_{i} d_{i g}^{\prime}(\cdot) \frac{1}{e_{i g}^{2}} d e_{i g}}{\int_{i}\left[y_{i g}^{\prime}(\cdot)-d_{i g}^{\prime}(\cdot)\right]}$. Noting that each term of the integral in the numerator has the same sign as $d e_{i g}$, it follows that if any subset of countries loosens their standards, the world price goes up.
} 
to symmetric, or if demand semi-elasticities $\sigma_{i g}$ do not vary too much with the price, or if the political parameters $\gamma_{i g}$ are sufficiently large. For the purposes of the next proposition we assume that at least one of these sufficient conditions is satisfied.

Proposition 3 The equilibrium agreement loosens all product standards.

Our model thus yields a sharp prediction: international regulatory cooperation should lead to less stringent product standards. The intuition behind this result is that, if a group of countries loosen their product standards, the world price goes up because demand increases, and this in turn generates two externalities on other countries: it benefits producer lobbies (political externality) and it mitigates local pollution (environmental externality). ${ }^{27}$

\subsection{Is it good for you?}

Recall from the discussion above that there are two motives from an agreement on product standards: a political reason and an environmental reason. Letting $\Delta_{g} \equiv W_{g}^{A}-W_{g}^{N}$ denote the (positive or negative) welfare change caused by the agreement relative to the noncooperative equilibrium, the political motive pushes $\Delta_{g}$ down, since lobbying pressures distort product standards in the cooperative scenario but not in the noncooperative scenario. Instead of the counter-lobbying we highlighted in the context of shallow integration, we now have co-lobbying of all producers world-wide, since they share a common interest in boosting the world price. The environmental motive, on the other hand, pushes $\Delta_{g}$ up: intuitively, if lobbying pressures were absent the agreement would be motivated just by welfare considerations, and hence $\Delta_{g}$ would be positive.

We illustrate the welfare implications of the agreement intuitively by focusing on the case in which countries are symmetric, and later we extend the result to the case of asymmetric countries. The key argument for the case of symmetric countries can be illustrated with the help of Figure $1 .^{28}$

\footnotetext{
${ }^{27}$ While the intuition outlined above suggests that this result should be fairly robust in a number of dimensions, it does rely on the assumption that there are no fixed costs of standards compliance. In the presence of such fixed costs, international cooperation might lead to the harmonization of standards (see for example Grossman et al., 2019), in which case standards would get looser in some countries and tighter in others. But even in such a setting, intuitively we expect that if lobbying pressures are strong enough the agreement will loosen product standards on average.

${ }^{28}$ The key features of Figure 1 are proved in the Appendix, within the proof of Proposition 4. In what follows we provide an intuitive explanation.
} 
Figure 1: Product Standards

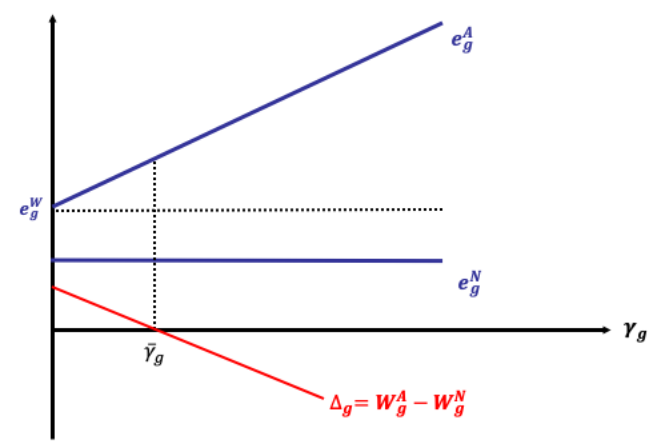

This figure draws the noncooperative standards $e_{g}^{N}$ and the cooperative standards $e_{g}^{A}$ as functions of the political-economy parameter $\gamma_{g}$. It also shows the welfare-maximizing standards $e_{g}^{W}$ and the welfare gain from the agreement, $\Delta_{g}=W_{g}^{A}-W_{g}^{N}$.

First note that the noncooperative standards do not depend on $\gamma_{g}$ and are tighter than the welfare-maximizing standards $\left(e_{g}^{N}<e_{g}^{W}\right) .{ }^{29}$ Intuitively, starting from the noncooperative equilibrium, loosening standards in a group of countries has a positive welfare externality on other countries, because it increases the world price and in turn mitigates the local consumption externalities in other countries. As a consequence, noncooperative standards are too tight from the welfare point of view.

The cooperative standards $e_{g}^{A}$ coincide with $e_{g}^{W}$ for $\gamma_{g}=0$ and are increasing in $\gamma_{g}$. Intuitively, stronger lobbying pressures lead to looser cooperative standards because producers worldwide benefit from a rise in the world price.

The welfare gain from the agreement $\left(\Delta_{g}\right)$ is of course positive at $\gamma_{g}=0$, but is decreasing in $\gamma_{g}$ and it becomes negative as $\gamma_{g}$ crosses a critical value $\bar{\gamma}_{g}$. Intuitively, as $\gamma_{g}$ increases, cooperative standards get looser and looser, and at some point the implied welfare distortion exceeds the welfare distortion in the over-tight noncooperative standards.

The result illustrated above for the case of symmetric countries extends to the case of asymmetric countries, albeit in a slightly weaker version. To state the more general result, we consider a proportional change in all political parameters $\gamma_{i g}$. Formally, we define $\gamma_{i g}=\gamma_{g} \cdot \nu_{i g}$ (with $\nu_{i g}>0$ for all $i, g$ ) and vary the scaling factor $\gamma_{g}$. In general it is not guaranteed that there is a unique value of $\gamma_{g}$ for which $\Delta_{g}=0$ as in Figure 1, but we can prove the following:

\footnotetext{
${ }^{29}$ This is an immediate corollary of Proposition 3, since the welfare-maximizing standards coincide with the cooperative standards when $\gamma_{g}=0$.
} 
Proposition 4 Cooperation on product standards increases global welfare if $\gamma_{g}$ is sufficiently low, and decreases global welfare if $\gamma_{g}$ is sufficiently high.

In our model international cooperation on product standards leads to de-regulation, in part because it induces "co-lobbying" from producer groups around the world. If lobbying pressures are weak, such de-regulation is mild and actually increases welfare, because noncooperative standards are too tight from the welfare point of view, but if lobbying pressures are strong, the agreement leads to excessive de-regulation and damages welfare.

We now return to a question raised earlier: how do the results change if consumption taxes are available? As mentioned earlier, the first best can be implemented by combining product standards with consumption taxes. In particular, it is easy to see that the firstbest variety is $e_{i g}=\frac{1}{\sqrt{a_{i g}}}$ and the first-best consumption tax is $t_{i g}=\sqrt{a_{i g}} \cdot{ }^{30}$ A key point is that these policies maximize not only global welfare, but also unilateral welfare, thus they are the noncooperative equilibrium policies. It is then an immediate corollary that the cooperative policies decrease welfare relative to the noncooperative policies. In particular, the cooperative policies can be shown to be $t_{i g}^{A}=\sqrt{a_{i g}}-\frac{\int_{i} \gamma_{i g} y_{i g}}{\int_{i} \varepsilon_{i g} y_{i g}}, e_{i g}^{A}=\frac{1}{\sqrt{a_{i g}}}$. Thus the availability of consumption taxes makes the conclusion more pessimistic: a deep agreement on product standards in this case is bad for welfare as long as there is any lobbying, and the welfare loss is worse if lobbying pressures are stronger.

Before proceeding, it is important to put the results of this section in the right perspective. As we mentioned in the Introduction, our model abstracts from considerations that could flip the sign of the welfare effect of the agreement, such as the presence of large countries, transboundary externalities or domestic-commitment motives, but regardless of the sign of the welfare change, the more robust result is that lobbying by producer groups tends to decrease the welfare gain (or increase the welfare loss) from an agreement on product standards. ${ }^{31}$

\footnotetext{
${ }^{30}$ One way to show that these policies implement the first best is to note that they are equivalent to the Pigouvian emission-contingent $\operatorname{tax} t_{i g}\left(e_{i g}\right)=a_{i g} e_{i g}$. To see this equivalence, note that given the Pigouvian emission-contingent tax schedule, consumers will buy only the variety with the minimum consumer price, and this is easily calculated to be $e_{i g}=\frac{1}{\sqrt{a_{i g}}}$. And conditional on this variety, the Pigouvian single-rate consumption tax is $t_{i g}=\sqrt{a_{i g}}$.

${ }^{31}$ Here we provide a brief intuitive discussion of one of these extensions, namely the presence of large countries. As a thought experiment, compare a world with a continuum of small countries with the same world split into a few large countries. Suppose first that countries are symmetric. If lobbying pressures are strong enough, non-cooperative standards are more inefficient in the large-country world, because an individual country wants to loosen its standards in order to increase the world price and benefit local producers. On the other hand, cooperative standards are the same in the small-country and large-country scenarios, since the world is the same in the aggregate. Thus, the threshold level of $\gamma_{g}$ beyond which the agreement is bad for welfare should be higher in the large-country scenario. Next suppose countries are asymmetric, so there is
} 


\section{Deep integration: process standards}

We now turn our attention to the welfare implications of agreements on process regulations. By "process regulations" or "process standards" we mean restrictions on the production processes that take place on domestic soil. Examples include environmental regulations for factories and safety standards for workers. As discussed above, process standards of this kind have been an important focus of many deep agreements in recent history.

To provide a welfare rationale for process standards we will allow for local production externalities. To make our points in the most transparent way, in this section we focus on a setting where process standards are the only policy instruments and production externalities are the only market failures.

\subsection{Setup}

We now assume that each good $g$ is homogenous but can be produced with a continuum of technologies $z_{g} \in[0, \infty)$, indexed by their "dirtiness." Dirtier production processes are cheaper: producers have to incur an abatement cost $1 / z_{g}$ in terms of the outside good in order to use technology $z_{g}$. From the point of view of an individual producer, aside from the abatement cost all technologies are identical.

Production generates a negative externality, which is worse for dirtier processes (higher $z_{g}$ ). For concreteness we will focus on pollution externalities as our running example. Since each producer is atomistic and hence does not take into account the pollution externality, the supply of good $g$ in country $i$ depends only on the local producer price $p_{i g}^{p}$, and will be denoted $y_{i g}\left(p_{i g}^{p}\right)$.

As will become clear, a single technology is used in equilibrium in each country $i$, say technology $z_{i g}$. Producing $y_{i g}$ units with technology $z_{i g}$ generates local pollution $z_{i g} y_{i g}$. This could be for example the amount of emissions from factories in country $i$. The disutility caused by a unit of pollution to the representative consumer of country $i$ is constant and denoted by $b_{i g}$, so the local externality is given by $-b_{i g} z_{i g} y_{i g}\left(p_{i g}^{p}\right){ }^{32}$

international trade in equilibrium. In this case there is also a terms-of-trade motive affecting a country's choice of standards: this motive pushes importers in the direction of tightening standards, while it pushes exporters toward looser standards. In the aggregate, terms-of-trade motives can make non-cooperative standards more or less efficient, but if the terms-of-trade power of importers and exporters is not too unbalanced, this should not overturn the conclusion of the symmetric case, namely that in a world of large countries the agreement is less likely to be bad for welfare.

${ }^{32} \mathrm{As}$ in the previous section, we are implicitly assuming that the disutility from pollution enters utility in a separable way. 
Each government chooses emission standards $\left\{z_{i g}\right\}_{g \in \mathcal{G}}$ for production activity taking place on domestic soil. These can be interpreted as emission caps, since caps are always binding; recall that adopting a cleaner technology is costly and does not directly benefit an individual producer.

Due to consumer arbitrage, the consumer price is the same across the world, and we denote it by $p_{g}$. This can be interpreted as the "world" price in this setting. The producer price net of abatement costs, on the other hand, is $p_{i g}^{p}=p_{g}-\frac{1}{z_{i g}}$. Thus, if an individual country $i$ tightens its process standards, the associated cost falls entirely on its producers. Notice the contrast with the case of product standards, where the cost of tighter standards falls on consumers.

Government $i$ 's objective can be written as:

$$
\Omega_{i}=\sum_{g \in \mathcal{G}}\left[\left(1+\gamma_{i g}\right) \pi_{i g}\left(p_{g}-\frac{1}{z_{i g}}\right)+S_{i g}\left(p_{g}\right)-b_{i g} z_{i g} y_{i g}\left(p_{g}-\frac{1}{z_{i g}}\right)\right],
$$

Note that, just as in the case of product standards, process standards are second-best policies, because given the process $z_{i g}$ producers do not internalize the production externality.

\subsection{Noncooperative process standards}

In the noncooperative scenario, government $i$ chooses the process standard in sector $g$ according to:

$$
\max _{z_{i g}} \Omega_{i g}=\left(1+\gamma_{i g}\right) \pi_{i g}\left(p_{g}-\frac{1}{z_{i g}}\right)+S_{i g}\left(p_{g}\right)-b_{i g} z_{i g} y_{i g}\left(p_{g}-\frac{1}{z_{i g}}\right)
$$

As in the previous section we assume that $\Omega_{i g}$ is concave in $e_{i g}$, so we can rely on the first-order conditions. It is easy to verify that the first-order conditions imply

$$
z_{i g}=-\frac{\varepsilon_{i g}}{2}+\sqrt{\left(\frac{\varepsilon_{i g}}{2}\right)^{2}+\frac{1}{b_{i g}}\left(1+\gamma_{i g}\right)} \text { for all } i
$$

The market clearing condition can be written as:

$$
\int_{i} y_{i g}\left(p_{g}-\frac{1}{z_{i g}}\right)=\int_{i} d_{i g}\left(p_{g}\right) .
$$

The noncooperative equilibrium process standards and world price for good $g$ solve equations (16) and (17). We assume that such solution exists and is unique, and denote it $\left(\left\{z_{i g}^{N}\right\}, p_{g}^{N}\right)$. 
A key difference between product and process standards can already be noted from (16): unlike the case of product standards, unilateral process standards are influenced by lobbies. The reason is that the process standard adopted by country $i$ directly affects the local producer price, so to the extent that local producers have political power, they will push for looser standards. ${ }^{33}$ Notice also that, if $\varepsilon_{i g}$ is held constant, noncooperative process standards are tighter $\left(z_{i g}^{N}\right.$ is lower) when production externalities are more important $\left(b_{i g}\right.$ is higher), as intuition would suggest.

\subsection{Cooperative process standards}

In the cooperative scenario, governments maximize their joint payoff taking into account the effect of process standards on world prices. Thus cooperative process standards in sector $g$ solve:

$$
\begin{gathered}
\max _{\left\{z_{i g}\right\}, p_{g}} \Omega_{g}=\int_{i}\left[\left(1+\gamma_{i g}\right) \pi_{i g}\left(p_{g}-\frac{1}{z_{i g}}\right)+S_{i g}\left(p_{g}\right)-b_{i g} z_{i g} y_{i g}\left(p_{g}-\frac{1}{z_{i g}}\right)\right] \\
\text { s.t. } \int_{i} y_{i g}\left(p_{g}-\frac{1}{z_{i g}}\right)=\int_{i} d_{i g}\left(p_{g}\right)
\end{gathered}
$$

As in the previous section, we assume that $\Omega_{g}\left(\mathbf{z}_{g}, p_{g}\left(\mathbf{z}_{g}\right)\right)$ is concave in $\mathbf{z}_{g}$, where $p_{g}\left(\mathbf{z}_{g}\right)$ denotes the market-clearing price as a function of the standards, and that there exists a solution to the system of first-order conditions below.

It is easy to check that the cooperative process standards and world price for good $g$ satisfy the following conditions (omitting the arguments of the various functions for simplicity):

$$
\begin{gathered}
z_{i g}=-\frac{\varepsilon_{i g}}{2}+\sqrt{\left(\frac{\varepsilon_{i g}}{2}\right)^{2}+\frac{1}{b_{i g}}\left(1+\gamma_{i g}-\lambda_{g} \varepsilon_{i g}\right)} \text { for all } i \\
\lambda_{g}=\frac{\int_{i} y_{i g}\left(\gamma_{i g}-b_{i g} z_{i g} \varepsilon_{i g}\right)}{\int_{i} \varepsilon_{i g} y_{i g}+\int_{i} \sigma_{i g} d_{i g}} \\
\int_{i} y_{i g}=\int_{i} d_{i g},
\end{gathered}
$$

where $\lambda_{g}$ denotes the Lagrange multiplier. We let $\left(\left\{z_{i g}^{A}\right\}, p_{g}^{A}, \lambda_{g}^{A}\right)$ denote the solution to the above system of equations.

\footnotetext{
${ }^{33}$ Note that, if we increase the local producers' political power $\gamma_{i g}$ holding all else equal, the unilateral standard $z_{i g}^{N}$ gets looser, but if we increase political powers in all countries at the same time, the world price will go down, and this may in turn affect the supply elasticity $\varepsilon_{i g}$. This will dampen or reinforce the impact on $z_{i g}^{N}$, depending on whether $\varepsilon_{i g}$ increases or decreases with the price.
} 
The key difference between noncooperative and cooperative process standards is the presence of the multiplier $\lambda_{g}$ in equation (19). Note that $\lambda_{g}$ is positive if $\gamma_{i g}>b_{i g} z_{i g} \varepsilon_{i g}$ for all $i$. This suggests that the agreement will tighten standards if lobbying pressures are sufficiently strong, and loosen standards if lobbying pressures are sufficiently weak. Intuitively, the agreement changes process standards for both political and environmental reasons, as in the case of product standards, but these two forces now push in opposite directions: the political motive pushes for a tightening of standards, because this would increase the world price and hence benefit all producers, while the environmental motive pushes for a loosening of standards, because this would decrease the world price and hence reduce production and pollution.

The intuition offered just above, however, does not take into account the fact that the expression for $\lambda_{g}$ depends on the optimal standards $z_{i g}$ themselves (as well as the supply elasticities, which in general depend on prices). Thus we need to go a bit deeper with the analysis.

\subsection{What does the agreement do?}

To examine how the agreement changes process standards, we start by considering the international externalities caused by a change in process standards when starting from the noncooperative equilibrium. If a group of countries tightens their standards, this reduces supply and hence pushes up the world price. ${ }^{34}$ How does this affect the joint payoff of all governments? Differentiating the joint government payoff $\Omega_{g}$ with respect to $p_{g}$ and evaluating at the noncooperative standards (10), we obtain:

$$
\left.\frac{\partial \Omega_{g}}{\partial p_{g}}\right|_{N E}=\int_{i}\left(\gamma_{i g} y_{i g}-b_{i g} z_{i g}^{N} \varepsilon_{i g} y_{i g}\right)
$$

The first term of (20) is positive and is due to the political externality exerted by the increase in the world price. The second term is negative and is due to the fact that a higher world price stimulates supply, thus increasing pollution world-wide. Intuitively, if lobbying pressures are strong the net externality should be positive, thus the agreement should tighten standards relative to the noncooperative equilibrium, while if lobbying pressures are weak, the net externality should be negative, so the agreement should loosen standards.

\footnotetext{
${ }^{34}$ To see this, differentiate the market clearing condition to get $d p_{g}=\frac{-\int_{i} y_{i g}^{\prime}(\cdot) \frac{1}{z_{i g}^{2}} d z_{i g}}{\int_{i}\left[y_{i g}^{\prime}(\cdot)-d_{i g}^{\prime}(\cdot)\right]}$. Noting that each term of the integral in the numerator has the opposite sign as $d z_{i g}$, it follows that if any subset of countries reduces their $z$ 's, the world price goes up.
} 
We can confirm this intuition, in the following sense. Consider a proportional change in the political parameters, by letting $\gamma_{i g}=\gamma_{g} \nu_{i g}$ and varying the scaling factor $\gamma_{g}$ (as in the previous section). First, it is obvious that if $\gamma_{g}$ is small enough then $\left.\frac{\partial \Omega_{g}}{\partial p_{g}}\right|_{N E}<0$. Next note that, as $\gamma_{g}$ increases, $z_{i g}^{N}$ increases with the speed of the square root. Recalling our assumption that $\varepsilon_{i g}$ is bounded, it follows immediately that $\left.\frac{\partial \Omega_{g}}{\partial p_{g}}\right|_{N E}>0$ if $\gamma_{g}$ is sufficiently large. It is then a small step to conclude, using a similar logic as in the previous section, that the local agreement loosens all standards if $\gamma_{g}$ is sufficiently small and tightens all standards if $\gamma_{g}$ is sufficiently large.

Similarly as in the case of product standards, we can show that this local result holds globally if countries are sufficiently close to symmetric, or if the supply semi-elasticities $\varepsilon_{i g}$ do not vary too much with the price. ${ }^{35}$ For the purposes of the following proposition we assume that at least one of these sufficient conditions is satisfied.

Proposition 5 The equilibrium agreement loosens all process standards if the political power of producers is sufficiently weak and tightens all process standards if the political power of producers is sufficiently strong.

One way to interpret this result is that, when lobbying pressures are strong, the noncooperative equilibrium entails a "race to the bottom," and the agreement acts to counterbalance this tendency. But note that, as should be clear from the analysis above, what drives the cooperative tightening of standards is the influence of producer groups themselves.

We are now ready to tackle the question of how international cooperation on process standards affects global welfare.

\subsection{Is it good for you?}

We start by describing briefly our main result and its underlying logic. We will show that the equilibrium agreement increases welfare if $\gamma_{g}$ is sufficiently small or sufficiently large, and may decrease welfare for intermediate values of $\gamma_{g}$. The starkest difference with respect to our earlier result for product standards is the fact that, when political pressures are strong $\left(\gamma_{g}\right.$ large), a deep agreement is bad for welfare in the case of product standards, while it is good for welfare in the case of process standards. The fundamental reason for this difference is that

\footnotetext{
${ }^{35}$ We can also show that, if $\gamma_{g}$ is sufficiently large, the globally optimal agreement tightens all process standards, regardless of country asymmetries or variable semi-elasticities. In other words, the second part of the local result holds globally without the need of further conditions. The proof of this claim can be found within the proof of Proposition 5.
} 
the interests of producers around the world are no longer aligned when it comes to process regulations, since each producer lobby prefers weak regulations at home and strict regulations abroad. As a result, the deep agreement now brings about counter-lobbying, thereby diluting the overall effect of lobbying on process standards. Notice how the nature of counter-lobbying here differs from the case of shallow integration that we analyzed in Section 2: there, the key political cleavage was between import-competing interests and export interests.

Also note that, in terms of underlying economic mechanisms, a key difference between product and process standards is that these two forms of regulation have opposite impacts on world prices: tightening product standards raises local consumer prices, hence reduces local demand and puts downward pressure on world prices; while tightening process standards reduces local producer net prices, hence reduces local supply and puts upward pressure on world prices.

We now illustrate in more detail the logic behind our result. We start by focusing on the special case in which countries are symmetric and the semi-elasticity of supply $\left(\varepsilon_{g}\right)$ is constant, and then we extend the result to the more general case. We illustrate our arguments with the help of Figure 2. ${ }^{36}$

Figure 2: Process Standards

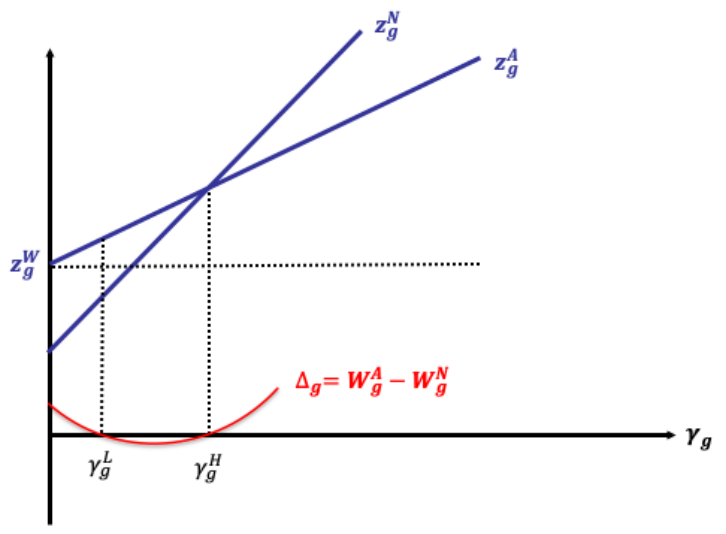

This figure shows the noncooperative standards $z_{g}^{N}$, the cooperative standards $z_{g}^{A}$ and the welfare maximizing standards $z_{g}^{W}$ as functions of $\gamma_{g}$, as well as the welfare change from the agreement, $\Delta_{g}=W_{g}^{A}-W_{g}^{N}$.

Absent lobbying pressures $\left(\gamma_{g}=0\right)$, noncooperative process standards are too tight from the welfare point of view $\left(z_{g}^{N}<z_{g}^{W}\right)$, since governments do not internalize the negative

\footnotetext{
${ }^{36}$ The key features of Figure 2 are proved formally in the Appendix, within the proof of Proposition 6.
} 
international externality caused by tightening standards. As $\gamma_{g}$ increases, noncooperative standards become looser, since loosening standards unilaterally benefits local producers. The cooperative standards $z_{g}^{A}$ coincide with the welfare-maximizing standards $z_{g}^{W}$ when $\gamma_{g}=0$ and are also increasing in $\gamma_{g}$. However, the $z_{g}^{A}$ schedule is flatter than the $z_{g}^{N}$ schedule, since in the cooperative scenario governments internalize the negative political terms-oftrade externality from loosening standards, and such externality becomes stronger as $\gamma_{g}$ increases. This captures the counter-lobbying intuition we mentioned earlier: looser domestic standards harm the interests of producers abroad, thus cooperation moderates the loosening of standards that is brought about by increases in lobbying pressures.

The welfare change from the agreement $\left(\Delta_{g}\right)$ is of course positive at $\gamma_{g}=0$, but more interestingly, it must be positive again for $\gamma_{g}$ large enough. The latter statement follows from the fact that if $\gamma_{g}$ is large enough then $z_{g}^{N}>z_{g}^{A}>z_{g}^{W}$, together with the assumption that welfare is concave in $z_{g}$. Furthermore, $\Delta_{g}$ must be negative for an intermediate range of $\gamma_{g}$ (in Figure 2 the interval between $\gamma_{g}^{L}$ and $\gamma_{g}^{H}$ ), because the noncooperative standards coincide with the welfare-maximizing standards for a critical value of $\gamma_{g}$. Thus the welfare change from the agreement is non-monotonic, being positive if lobbying pressures are low or high, but negative when lobbying pressures are intermediate.

The result illustrated just above generalizes to the case of asymmetric countries and variable semi-elasticities, albeit in a slightly weaker version. The only change is that in general there may or may not be an intermediate range of $\gamma_{g}$ for which the agreement decreases welfare. In order to state the more general result, we consider as usual a proportional change in all political parameters $\gamma_{i g}$, with $\gamma_{g}$ denoting the scaling factor:

Proposition 6 Cooperation on process standards increases global welfare if $\gamma_{g}$ is sufficiently low or sufficiently high, and may decrease global welfare for intermediate values of $\gamma_{g}$.

As discussed above, the result that the equilibrium agreement increases global welfare when lobbying is strong enough contrasts sharply with the case of product standards, and the basic reason is that international negotiations bring about countervailing lobbying between the domestic producers of a given country and the producers in the remaining countries. ${ }^{37}$

\footnotetext{
${ }^{37}$ One possible concern is that, if there is countervailing lobbying and lobbies are worse off in the cooperative scenario than in the non-cooperative equilibrium, they may oppose participation in the agreement at the exante stage (we thank Dani Rodrik for raising this point). One way to think about this issue is the following. Suppose that in each country the government and the lobbies negotiate ex-ante on whether to participate in the agreement. In this negotiation, the outside option of the government is to go ahead and sign an agreement without the lobbies, and moreover, all governments and lobbies are jointly better off under the agreement
} 
It is also worth emphasizing a subtle aspect of the result in Proposition 6: in spite of the countervailing-lobbying effect, the agreement may decrease welfare for an intermediate range of lobbying pressures (and as noted above, this intermediate range of $\gamma_{g}$ is guaranteed to exist if countries are symmetric). The intuition is the following: if governments are welfaremaximizers $\left(\gamma_{g}=0\right)$, noncooperative standards are too tight, so a moderate amount of political pressures makes noncooperative standards more efficient, and there is a critical level of $\gamma_{g}$ that makes them exactly efficient $\left(z_{g}^{N}=z_{g}^{W}\right.$ in Figure 2). Clearly, then, for $\gamma_{g}$ close to this critical level the agreement must be bad for welfare. ${ }^{38}$

Finally, what does the model suggest regarding the impact of lobbying on the welfare change from the agreement $\left(\Delta_{g}\right)$ ? Recall that, in the case of product standards, increasing the power of lobbies reduces $\Delta_{g}$ (see Figure 1). Here the answer is different and more subtle, as Figure 2 suggests: increasing the power of lobbies initially worsens the welfare implications of the agreement, but this effect is reversed as the power of lobbies becomes large.

\section{Integrated Model}

Thus far we have examined the implications of international cooperation on product and process standards with the aid of two separate models. We now consider an integrated model to explore the interactions between these two dimensions of deep integration in a setting with both consumption and production externalities. We maintain the assumption that shallow integration has previously been achieved and tariffs have been eliminated.

We essentially merge the economic structures that we considered in sections 3 and 4 , by allowing for a continuum of varieties and a continuum of technologies. If country $i$ imposes product standard $e_{i g}$ and process standard $z_{i g}$, international arbitrage ensures that the local consumer price is $p_{g}+\frac{1}{e_{i g}}$ and the local producer price is $p_{g}-\frac{1}{z_{i g}}$, where $p_{g}$ can be interpreted as the "world price," or alternatively, the price that producers and consumers of country $i$ would face if country $i$ imposed no standards $\left(e_{i g}=z_{i g}=\infty\right)$. The local consumption and production externalities associated with these standards are respectively $-a_{i g} e_{i g} d_{i g}$ and

than in the non-cooperative equilibrium. This suggests that an agreement will be signed even if it makes lobbies worse off (and governments do not have to compensate lobbies for taking this course of action, since their outside option is to sign the agreement).

${ }^{38} \mathrm{On}$ a separate note, the reader might wonder how our results on process standards would change if we allowed for production taxes. But recall that if production subsidies (i.e. negative production taxes) were available, lobbies would focus only on production subsidies, thus the model would have nothing to say about the impact of lobbying on regulations. This is the same issue that arises if production subsidies are allowed together with tariffs. For this reason, we follow most of the literature in assuming away production taxes/subsidies. 
$-b_{i g} z_{i g} y_{i g}$.

In the noncooperative scenario, government $i$ chooses standards in sector $g$ to solve the following problem:

$$
\max _{\left\{e_{i g}, z_{i g}\right\}} \Omega_{i g}=\left(1+\gamma_{i g}\right) \pi_{i g}\left(p_{g}-\frac{1}{z_{i g}}\right)+S_{i g}\left(p_{g}+\frac{1}{e_{i g}}\right)-a_{i g} e_{i g} d_{i g}\left(p_{g}+\frac{1}{e_{i g}}\right)-b_{i g} z_{i g} y_{i g}\left(p_{g}-\frac{1}{z_{i g}}\right) .
$$

Simple algebra reveals that the noncooperative standards and world price for good $g$ satisfy:

$$
\begin{gathered}
e_{i g}=-\frac{\sigma_{i g}}{2}+\sqrt{\left(\frac{\sigma_{i g}}{2}\right)^{2}+\frac{1}{a_{i g}}} \text { for all } i \\
z_{i g}=-\frac{\varepsilon_{i g}}{2}+\sqrt{\left(\frac{\varepsilon_{i g}}{2}\right)^{2}+\frac{1}{b_{i g}}\left(1+\gamma_{i g}\right)} \text { for all } i \\
\int_{i} y_{i g}=\int_{i} d_{i g}
\end{gathered}
$$

In the cooperative scenario, on the other hand, the standards and world price for good $g$ solve:

$$
\begin{gathered}
\max _{\left\{e_{i g}, z_{i g}\right\}, p_{g}} \Omega_{g}=\int_{i}\left\{\left(1+\gamma_{i g}\right) \pi_{i g}\left(p_{g}-\frac{1}{z_{i g}}\right)+S_{i g}\left(p_{g}+\frac{1}{e_{i g}}\right)-a_{i g} e_{i g} d_{i g}\left(p_{g}+\frac{1}{e_{i g}}\right)-b_{i g} z_{i g} y_{i g}\left(p_{g}-\frac{1}{z_{i g}}\right)\right. \\
\text { s.t. } \int_{i} y_{i g}\left(p_{g}-\frac{1}{z_{i g}}\right)=\int_{i} d_{i g}\left(p_{g}+\frac{1}{e_{i g}}\right)
\end{gathered}
$$

It is easy to verify that the cooperative policies and world prices satisfy:

$$
\begin{gathered}
e_{i g}=-\frac{\sigma_{i g}}{2}+\sqrt{\left(\frac{\sigma_{i g}}{2}\right)^{2}+\frac{1}{a_{i g}}\left(1+\sigma_{i g} \lambda_{g}\right)} \text { for all } i \\
z_{i g}=-\frac{\varepsilon_{i g}}{2}+\sqrt{\left(\frac{\varepsilon_{i g}}{2}\right)^{2}+\frac{1}{b_{i g}}\left(1+\gamma_{i g}-\varepsilon_{i g} \lambda_{g}\right)} \text { for all } i \\
\lambda_{g}=\frac{\int_{i}\left(\gamma_{i g} y_{i g}+a_{i g} e_{i g} \sigma_{i g} d_{i g}-b_{i g} z_{i g} \varepsilon_{i g} y_{i g}\right)}{\int_{i}\left(\varepsilon_{i g} y_{i g}+\sigma_{i g} d_{i g}\right)} \\
\int_{i} y_{i g}=\int_{i} d_{i g},
\end{gathered}
$$

where $\lambda_{g}$ as usual denotes the Lagrange multiplier. Note that $\lambda_{g}$ now reflects the effect of a change in the world price on the joint government payoff through three channels: the political channel, the consumption-externality channel and the production-externality channel. 
We now examine how the agreement changes standards relative to the noncooperative equilibrium. Here we focus on the "local" agreement. As in the previous sections, the local results hold globally under certain sufficient conditions.

The first step is to understand how the local agreement changes the world price. This depends on how a small change in the world price affects the governments' joint payoff. It is immediate to verify that:

$$
\left.\frac{\partial \Omega_{g}}{\partial p_{g}}\right|_{N E}=\int_{i}\left(\gamma_{i g} y_{i g}+a_{i g} e_{i g}^{N} \sigma_{i g} d_{i g}-b_{i g} z_{i g}^{N} \varepsilon_{i g} y_{i g}\right)
$$

The local agreement leads to an increase in the world price if and only if $\left.\frac{\partial \Omega_{g}}{\partial p_{g}}\right|_{N E}>0$. We can already make two observations. The first one is that, in each sector $g$, the local agreement loosens all product standards $e_{i g}$ and tightens all process standards $z_{i g}$ if $\left.\frac{\partial \Omega_{g}}{\partial p_{g}}\right|_{N E}>0$, and vice-versa if $\left.\frac{\partial \Omega_{g}}{\partial p_{g}}\right|_{N E}<0$. This is a consequence of the fact that loosening product standards increases $p_{g}$, while loosening process standards decreases $p_{g}$. Thus the local agreement always changes product standards and process standards in opposite directions.

The second observation is that, if lobbying pressures are sufficiently strong, the local agreement loosens all product standards and tightens all process standards. It is easy to show, following a similar logic as in the previous section, that the positive term $\int_{i} \gamma_{i g} y_{i g}$ in (21) must outweigh the negative term $-\int_{i} b_{i g} z_{i g}^{N} \varepsilon_{i g} y_{i g}$ if the $\gamma_{i g}$ parameters are blown up sufficiently.

We can say something more if we impose symmetry across countries and constant semielasticities. First, in this case it is easy to show that the local results described just above are guaranteed to hold globally. Second, there exists a threshold $\tilde{\gamma}_{g} \geq 0$ such that the agreement tightens product standards and loosens process standards if $\gamma_{g} \in\left(0, \tilde{\gamma}_{g}\right)$ (with the range $\left(0, \tilde{\gamma}_{g}\right)$ possibly empty), and vice-versa if $\gamma_{g}>\tilde{\gamma}_{g} \cdot{ }^{39}$ The cooperative and noncooperative standards are depicted as functions of $\gamma_{g}$ in Figure 3, which focuses on the case where the interval $\left(0, \tilde{\gamma}_{g}\right)$ is nonempty (the fact that we have drawn the $z_{g}$ schedules above the $e_{g}$ schedules has no significance).

\footnotetext{
${ }^{39}$ To see this, first note from (21) that the agreement increases $e_{g}$ and decreases $z_{g}$ if $\gamma_{g}+a_{g} \sigma_{g} e_{g}^{N}-b_{g} \varepsilon_{g} z_{g}^{N}>$ 0 (where we used $d_{g}=y_{g}$ from symmetry and market clearing), and vice-versa if $\gamma_{g}+a_{g} \sigma_{g} e_{g}^{N}-b_{g} \varepsilon_{g} z_{g}^{N}<0$. Next observe that there can be at most one value of $\gamma_{g}$ such that $\gamma_{g}+a_{g} \sigma_{g} e_{g}^{N}-b_{g} \varepsilon_{g} z_{g}^{N}=0$. This is because $\frac{\partial\left(\gamma_{g}+a_{g} \sigma_{g} e_{g}^{N}\right)}{\partial \gamma_{g}}=1$ (recalling that $e_{g}^{N}$ is independent of $\gamma_{g}$ ) and $b_{g} \varepsilon_{g} z_{g}^{N}$ is concave in $\gamma_{g}$, with $\left.\frac{\partial\left(b_{g} \varepsilon_{g} z_{g}^{N}\right)}{\partial \gamma_{g}}\right|_{\gamma_{g}=0}<1$. The claim follows immediately.
} 
Figure 3: Product and Process Standards

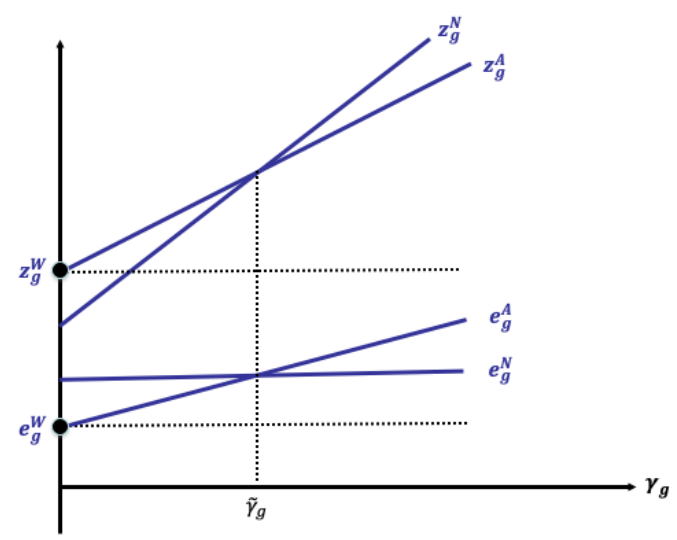

Note the two additional results that emerge relative to the previous sections, where product and process standards were analyzed separately. First, the agreement always changes product and process standards in opposite directions. And second, when lobbying pressures are weak, there are two new possibilities that could not arise when standards were considered in isolation: (i) the agreement may tighten product standards (if the interval $\left(0, \tilde{\gamma}_{g}\right)$ is nonempty, as in Figure 3), and (ii) the agreement may tighten process standards (if the interval $\left(0, \tilde{\gamma}_{g}\right)$ is empty, a case not considered in Figure 3$)$.

Next we consider the welfare impacts of regulatory cooperation. We continue to focus on the case of symmetric countries and constant semi-elasticities.

For $\gamma_{g}=0$, and hence for $\gamma_{g}$ small enough, the agreement is obviously good for welfare. The more interesting question is what happens for large $\gamma_{g}$. We can show that, when $\gamma_{g}$ is large, the agreement decreases global welfare if the production externality parameter $b_{g}$ is small enough (relative to the other parameters), while it increases global welfare if the consumption externality parameter $a_{g}$ is small enough (relative to the other parameters). Intuitively, if $b_{g}=0$ then no process standards are imposed, either in the non-cooperative equilibrium or in the cooperative scenario, so the model essentially reduces to the productstandards-only setting of Section 3, where the agreement is bad for welfare if $\gamma_{g}$ is large; and the same is true if $b_{g}$ is small enough. A similar intuition applies for the case in which the consumption externality parameter $a_{g}$ is small. Thus, when lobbying pressures are strong, the agreement is bad for welfare if the relative importance of production externalities versus consumption externalities is small, because in this case process standards play a small role relative to product standards, while it is good for welfare in the opposite case. 


\section{International ownership linkages}

For many critics of deep integration agreements, the influence of industry lobbies is synonymous with the power of multinational corporations. While our model cannot directly speak to the role of multinational corporations, since there is no meaningful notion of firms in our perfect-competition setting, we can easily allow for foreign ownership of production factors in our model. In this section, we therefore examine how the presence of international ownership linkages affects the main results we obtained so far.

To this end, we now assume that citizens of country $i$ own a share $\theta_{i j g}$ of the specific factor in country $j$ and thus receive a share $\theta_{i j g}$ of the rents $\pi_{j g}$ associated with it. As a

result, the producer surplus relevant for country $i$ 's government is no longer $\pi_{i g}$ but $\int_{j} \theta_{i j g} \pi_{j g}$, since these are now the rents that accrue to country $i$ 's citizens. We build directly on our integrated model from the previous section and focus on the case of constant semi-elasticities for simplicity.

Consider first the noncooperative scenario. For each sector $g$, government $i$ solves:

$$
\max _{\left\{e_{i g}, z_{i g}\right\}} \Omega_{i g}=\left(1+\gamma_{i g}\right) \int_{j} \theta_{i j g} \pi_{j g}(\cdot)+S_{i g}(\cdot)-a_{i g} e_{i g} d_{i g}(\cdot)-b_{i g} z_{i g} y_{i g}(\cdot)
$$

The noncooperative standards can be easily derived to be:

$$
\begin{gathered}
e_{i g}^{N}=-\frac{\sigma_{i g}}{2}+\sqrt{\left(\frac{\sigma_{i g}}{2}\right)^{2}+\frac{1}{a_{i g}}} \\
z_{i g}^{N}=-\frac{\varepsilon_{i g}}{2}+\sqrt{\left(\frac{\varepsilon_{i g}}{2}\right)^{2}+\frac{\theta_{i i g}}{b_{i g}}\left(1+\gamma_{i g}\right)}
\end{gathered}
$$

Not surprisingly, noncooperative product standards $e_{i g}^{N}$ are exactly the same as in the absence of foreign ownership. This is because governments cannot use product standards to affect local producer prices in our small country setting, so the ownership of specific factors does not matter.

Noncooperative process standards $z_{i g}^{N}$, on the other hand, are affected by international ownership linkages. In particular, $z_{i g}^{N}$ is increasing in the domestic ownership share $\theta_{i i g}$. Intuitively, in the presence of foreign ownership the government has stronger incentives to tighten process standards, since more of the costs are borne by foreign citizens. Note also that noncooperative process standards are less sensitive to the political parameters $\gamma_{i g}$ than in the absence of foreign ownership. This is because a government can only affect domesticallygenerated producer surplus with its choice of standards, and foreign ownership implies that only a share of this surplus accrues to domestic citizens. 
We can now focus on the cooperative standards. These solve the following problem:

$$
\begin{gathered}
\max _{\left\{e_{i g}, z_{i g}\right\}, p_{g}} \Omega_{g}=\int_{i}\left[\left(1+\gamma_{i g}\right) \int_{j} \theta_{i j g} \pi_{j g}(\cdot)+S_{i g}(\cdot)-a_{i g} e_{i g} d_{i g}(\cdot)-b_{i g} z_{i g} y_{i g}(\cdot)\right] \\
\text { s.t. } \int_{i} y_{i}(\cdot)=\int_{i} d_{i}(\cdot)
\end{gathered}
$$

This yields:

$$
\begin{gathered}
e_{i g}^{A}=-\frac{\sigma_{i g}}{2}+\sqrt{\left(\frac{\sigma_{i g}}{2}\right)^{2}+\frac{1}{a_{i g}}\left(1+\sigma_{i g} \lambda_{g}\right)} \\
z_{i g}^{A}=-\frac{\varepsilon_{i g}}{2}+\sqrt{\left(\frac{\varepsilon_{i g}}{2}\right)^{2}+\frac{1}{b_{i g}}\left(1+\int_{j} \gamma_{j g} \theta_{j i g}-\varepsilon_{i g} \lambda_{g}\right)} \\
\lambda_{g}=\frac{\int_{i}\left(\int_{j} \gamma_{j g} \theta_{j i g} y_{i g}+a_{i g} e_{i g}^{A} \sigma_{i g} d_{i g}-b_{i g} z_{i g}^{A} \varepsilon_{i g} y_{i g}\right)}{\int_{i}\left(y_{i g} \varepsilon_{i g}+\sigma_{i g} d_{i g}\right)}
\end{gathered}
$$

Notice that, if lobbying powers do not vary across countries (i.e. $\gamma_{i g}=\gamma_{g}$ for all $i$ ), cooperative standards are the same as in the absence of foreign ownership. Intuitively, in this case what matters for the governments' joint payoff is worldwide producer surplus, not the distribution of producer surplus across countries. On the other hand, if lobbying powers vary across countries, foreign ownership does affect cooperative standards, because now the producer surplus generated in a given country $\left(\pi_{i g}\right)$ is weighted by the countryspecific political parameters $\gamma_{j g}$ according to their respective foreign ownership shares $\theta_{j i g}$.

Focusing on the case of symmetric countries, we can depict the cooperative and noncooperative standards as functions of $\gamma_{g}$ with the help of Figure 4:

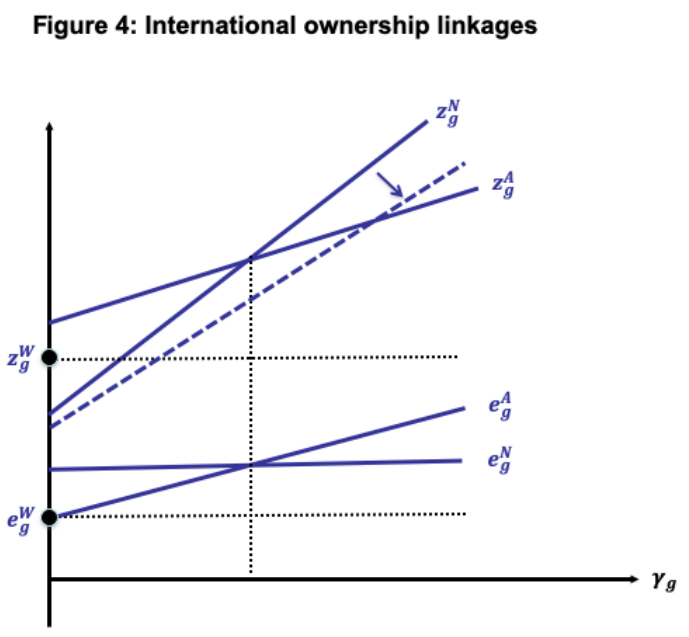


As Figure 4 illustrates, introducing foreign ownership implies only one change: the $z_{g}^{N}$ schedule shifts down and becomes flatter (as illustrated by the dashed line in Figure 4), and as a consequence, the agreement loosens process standards for a larger interval of $\gamma_{g}$ relative to the setting without foreign ownership. With this observation in hand, we can now examine how foreign ownership affects the welfare impacts of regulatory cooperation.

We continue to focus on the case of symmetric countries for simplicity. In this case, the importance of foreign ownership is captured by a single parameter (for each sector $g$ ), namely the foreign ownership share $1-\theta_{i i g} \equiv 1-\theta_{g}$. Clearly, an increase in the foreign ownership share reduces the welfare gains (or increases the welfare losses) from regulatory cooperation, at least if lobbying is sufficiently strong. The reason can be seen from Figure 4: if $\gamma_{g}$ is large enough, the introduction of foreign ownership pushes noncooperative process standards closer to their welfare-maximizing levels, without affecting anything else, and therefore the welfare gain from cooperation must decrease.

It is worth emphasizing two points in relation to this result. First, foreign ownership does not reduce the welfare gains from international cooperation because the cooperative outcome has deteriorated, but rather because the noncooperative equilibrium has improved. Second, this is only true for sufficiently high $\gamma_{g}$; indeed the opposite holds if $\gamma_{g}$ is sufficiently low. At $\gamma_{g}=0$, for example, foreign ownership pushes process standards away from their efficient levels, so the welfare gains from international cooperation increase. This also illustrates how our result differs from related results by Blanchard (2010) and Blanchard et al. (2018), where foreign ownership always improves the efficiency of the noncooperative equilibrium by inducing countries to internalize part of the terms-of-trade externalities they impose on their trading partners. In our setting, terms-of-trade considerations do not drive noncooperative policy choices, so this logic does not apply.

Finally notice that, while in the absence of foreign ownership a country's choice of standards affects other countries only through world prices, in the presence of foreign ownership there is an additional channel of international externality. A country's choice of process standards (but not of product standards) affects other countries through local prices. For this reason, the agreement corrects process standards in two ways relative to the noncooperative equilibrium: one is reflected by the multiplier $\lambda_{g}$, which is linked to the world-price externality; and one is reflected in the fact that, if we set $\lambda_{g}=0$, the cooperative standards $z_{g}^{A}$ are still different - and in particular they are looser - than the noncooperative standards $z_{g}^{N}$. Also note that this is the reason why in the absence of foreign ownership the agreement 
always changes product and process standards in opposite directions, while this is not the case here.

\section{Conclusion}

In this paper we have examined the welfare impacts of international regulatory cooperation in a world where producer lobbies can influence international negotiations. The welfare effects of international cooperation can be very different depending on whether it focuses on product standards or on process standards. International cooperation on product standards can decrease welfare, and this is more likely to happen when producer lobbies are stronger. On the other hand, international cooperation on process standards tends to increase welfare when lobbying pressures are strong. At a broad level, a key determinant of the welfare impact of deep agreements is whether the distortionary impact of lobbying is stronger in the noncooperative scenario or in the context of international negotiations. This in turn depends crucially on whether the policy interests of producer lobbies in different countries are aligned or in conflict: the former situation tends to occur in the case of product standards, while the latter situation tends to occur in the case of production regulations.

There are several extensions of our model that would be interesting to explore in future research. First, we have abstracted from fixed costs of compliance with product standards. Such fixed costs are undoubtedly relevant and often mentioned as a rationale for international harmonization of standards. Revisiting our questions in the presence of such fixed costs would require a model with imperfect competition, and the key intuitions might change in major ways relative to the present paper. Second, we have not considered horizontal standards. Note that the notions of co-lobbying and counter-lobbying, which are central in our model, are intrinsically vertical notions (do lobbies agree on tightening versus loosening standards), so they would not apply to a setting of horizontal standards, and hence one would have to entirely revisit the question of whether lobbying has a more distortionary effect on cooperative policies or on unilateral policies.

Another important question that we have not addressed in this paper is the role of global supply chains. Intuitively, in the presence of global supply chains, the welfare effects of regulatory cooperation would depend on where regulations hit along the supply chain. For example, consider vertical product standards. The interests of producer lobbies around the world are likely to be aligned when it comes to standards on final products, so regulatory cooperation will strengthen the impact of lobbies on regulations. But this would not nec- 
essarily be true for standards on intermediate products, because in this case the interests of upstream and downstream lobbies worldwide would be in conflict, so an agreement may dilute the overall influence of lobbies.

Finally, we have focused on global agreements, but it would be interesting to explore the welfare impacts of regional agreements when such agreements are negotiated under lobbying pressures. While there is a large literature that examines the welfare impacts of regional agreements of the "shallow" kind, including a few models where such agreements are negotiated under political pressure (e.g. Grossman and Helpman, 1995b, and Ornelas, 2005), the literature has paid little attention so far to the welfare impacts of regional regulatory cooperation. 


\section{Appendix}

\section{Proof of Proposition 1}

Let $f_{i g}\left(p_{g}+\tau_{i g}\right) \equiv \frac{\gamma_{i g} y_{i g}\left(p_{g}+\tau_{i g}\right)}{-m_{i g}^{\prime}\left(p_{g}+\tau_{i g}\right)}$ and let $\left(\left\{\hat{\tau}_{i g}\left(\kappa_{g}\right)\right\}_{i \in \mathcal{M}_{g}}, \hat{p}_{g}\left(\kappa_{g}\right)\right)$ denote the solution to the following system:

$$
\begin{gathered}
\tau_{i g}=f_{i g}\left(p_{g}+\tau_{i g}\right)-\kappa_{g}, \quad i \in \mathcal{M}_{g} \\
\int_{i \in \mathcal{M}_{g}} m_{i g}\left(p_{g}+\tau_{i g}\right)=\int_{i \in \mathcal{X}_{g}} x_{i g}\left(p_{g}\right)
\end{gathered}
$$

Note that $\kappa_{g}$ is a parameter that "connects" the noncooperative equilibrium with the cooperative solution. When $\kappa_{g}=0$ the solution of the above system is the noncooperative equilibrium, and when $\kappa_{g}=\lambda_{g}$ the solution of the above system coincides with the cooperative solution.

It is not hard to see that, given the assumption that there exists a unique solution to the above system for any $\kappa_{g} \in\left[0, \lambda_{g}\right]$ (stated in footnote 17), we must have $f_{i g}^{\prime}<1$ for all $i$ when evaluated at the solution of the system. Differentiating the above system we obtain:

$$
\begin{aligned}
\frac{\partial \hat{\tau}_{i g}}{\partial \kappa_{g}} & =\frac{f_{i g}^{\prime}}{1-f_{i g}^{\prime}} \frac{\partial \hat{p}_{g}}{\partial \kappa_{g}}-\frac{1}{1-f_{i g}^{\prime}} \\
\frac{\partial \hat{p}_{g}}{\partial \kappa_{g}} & =\frac{\int_{i \in \mathcal{M}_{g}} m_{i g}^{\prime} \frac{\partial \hat{\tau}_{i g}}{\partial \kappa_{g}}}{\int_{i \in \mathcal{X}_{g}} x_{i g}^{\prime}-\int_{i \in \mathcal{M}_{g}} m_{i g}^{\prime}}
\end{aligned}
$$

This yields:

$$
\begin{aligned}
\frac{\partial \hat{\tau}_{i g}}{\partial \kappa_{g}} & =-\frac{1}{1-f_{i g}^{\prime}} \frac{\int_{i \in \mathcal{X}_{g}} x_{i g}^{\prime}-\left(1-f_{i g}^{\prime}\right) \int_{i \in \mathcal{M}_{g}} m_{i g}^{\prime} \frac{1}{1-f_{i g}^{\prime}}}{\int_{i \in \mathcal{X}_{g}} x_{i g}^{\prime}-\int_{i \in \mathcal{M}_{g}} m_{i g}^{\prime} \frac{1}{1-f_{i g}^{\prime}}}<0 \\
\frac{\partial \hat{p}_{g}}{\partial \kappa_{g}} & =\frac{-\int_{i \in \mathcal{M}_{g}} m_{i g}^{\prime} \frac{1}{1-f_{i g}^{\prime}}}{\int_{i \in \mathcal{X}_{g}} x_{i g}^{\prime}-\int_{i \in \mathcal{M}_{g}} m_{i g \frac{1}{1-f_{i g}^{\prime}}}^{\prime}}>0
\end{aligned}
$$

Thus, as we move from the noncooperative equilibrium to the cooperative equilibrium, $\hat{\tau}_{i g}$ decreases for all $i$, and $p_{g}$ increases. We can conclude that $\tau_{i g}^{A}<\tau_{i g}^{N}$ for all $i$. QED

\section{Proof of Proposition 2}

We build on our proof of Proposition 1. First note that, using the expressions for $\frac{\partial \hat{\tau}_{i g}}{\partial \kappa_{g}}$ and $\frac{\partial \hat{p}_{g}}{\partial \kappa_{g}}$ obtained above yields:

$$
\frac{\partial\left(\hat{p}_{g}+\hat{\tau}_{i g}\right)}{\partial \kappa_{g}}=-\frac{\frac{1}{1-f_{i g}^{\prime}} \int_{i \in \mathcal{X}_{g}} x_{i g}^{\prime}}{\int_{i \in \mathcal{X}_{g}} x_{i g}^{\prime}-\int_{i \in \mathcal{M}_{g}} m_{i g}^{\prime} \frac{1}{1-f_{i g}^{\prime}}}<0
$$


Thus, as we move from the noncooperative equilibrium to the cooperative equilibrium, the domestic price decreases in each importing country.

We can now trace how global welfare changes as $\kappa_{g}$ changes. The global welfare associated with $\left(\left\{\hat{\tau}_{i g}\left(\kappa_{g}\right)\right\}_{i \in \mathcal{M}_{g}}, \hat{p}_{g}\left(\kappa_{g}\right)\right)$ can be written as:

$$
\hat{W}_{g}\left(\kappa_{g}\right)=\int_{i}\left[\pi_{i g}\left(\hat{p}_{g}+\hat{\tau}_{i g}\right)+S_{i g}\left(\hat{p}_{g}+\hat{\tau}_{i g}\right)+\hat{\tau}_{i g} m_{i g}\left(\hat{p}_{g}+\hat{\tau}_{i g}\right)\right],
$$

where we keep in mind, here and below, that $\hat{p}_{g}$ and $\hat{\tau}_{i g}$ are functions of $\kappa_{g}$. Differentiating with respect to $\kappa_{g}$, we obtain:

$$
\frac{\partial \hat{W}_{g}}{\partial \kappa_{g}}=\int_{i \in \mathcal{M}_{g}} \hat{\tau}_{i g} m_{i g}^{\prime}\left(\hat{p}_{g}+\hat{\tau}_{i g}\right) \frac{\partial\left(\hat{p}_{g}+\hat{\tau}_{i g}\right)}{\partial \kappa_{g}}
$$

This implies that the welfare change caused by the agreement is:

$$
W_{g}^{A}-W_{g}^{N}=\int_{0}^{\lambda_{g}}\left[\int_{i \in \mathcal{M}_{g}} \hat{\tau}_{i g} m_{i g}^{\prime}\left(\hat{p}_{g}+\hat{\tau}_{i g}\right) \frac{\partial\left(\hat{p}_{g}+\hat{\tau}_{i g}\right)}{\partial \kappa_{g}}\right] d \kappa_{g}
$$

Recalling that $m_{i g}^{\prime}<0, \frac{\partial\left(\hat{p}_{g}+\hat{\tau}_{i g}\right)}{\partial \kappa_{g}}<0$, and $\hat{\tau}_{i g}$ goes from the noncooperative level to the cooperative level as $\kappa_{g}$ goes from 0 to $\lambda_{g}$, it follows that a sufficient condition for $W_{g}^{A}-W_{g}^{N}>0$ is that cooperative tariffs are not too negative. QED

\section{Proof of Proposition 3}

We first establish that the local agreement increases $e_{i g}$ for all $i$. This follows from two observations. The first one is that $\Omega_{g}$ is increasing in each $e_{i g}$ when evaluated at the noncooperative standards. To see this, differentiate $\Omega_{g}$ to get:

$$
\begin{aligned}
d \Omega_{g} & =\int_{i}\left[\frac{\partial \Omega_{i g}}{\partial e_{i g}} d e_{i g}+\frac{\partial \Omega_{i g}}{\partial p_{g}} d p_{g}\right] \\
& =\int_{i}\left[\frac{\partial \Omega_{i g}}{\partial e_{i g}} d e_{i g}+\frac{\partial \Omega_{i g}}{\partial p_{g}} \cdot \frac{\int_{i}-d_{i g}^{\prime}(\cdot) \frac{1}{e_{i g}^{2}} d e_{i g}}{\int_{i}\left[y_{i g}^{\prime}(\cdot)-d_{i g}^{\prime}(\cdot)\right]}\right]
\end{aligned}
$$

Note that $\frac{\partial \Omega_{i g}}{\partial e_{i g}}=0$ for all $i$ at the noncooperative equilibrium and recall $\frac{\partial \Omega_{i g}}{\partial p_{g}}>0$ from the main text. Furthermore, each term of the integral at the numerator has the same sign as $d e_{i g}$, hence the claim. The second observation is that, since the gradient of $\Omega_{g}$ at the noncooperative standards $\mathbf{e}_{g}^{N}$ is positive for all standards, it follows that the direction of steepest ascent of the objective $\Omega_{g}$ starting from $\mathbf{e}_{g}^{N}$ entails loosening all of the standards.

Next we show that this local result holds globally if (i) countries are sufficiently close to symmetric, or (ii) demand semi-elasticities $\sigma_{i g}$ do not vary too much with the price, or (iii) the political economy parameters $\gamma_{i g}$ are sufficiently large. 
(i) Suppose that countries are symmetric. Given our regularity assumptions, it is easy to show that the noncooperative standards as well as the cooperative standards are symmetric; we denote them as $e_{g}^{N}$ and $e_{g}^{A}$ respectively. Note that, letting $\Omega_{g}\left(e_{g}, p_{g}\left(e_{g}\right)\right)$ denote the joint government payoff given a common standard $e_{g}$, this function is maximized by $e_{g}^{A}$. Also note that our assumption that $\Omega_{g}\left(\mathbf{e}_{g}, p_{g}\left(\mathbf{e}_{g}\right)\right)$ is concave in the vector of standards $\mathbf{e}_{g}$ implies that $\Omega_{g}\left(e_{g}, p_{g}\left(e_{g}\right)\right)$ is concave in $e_{g}$.

We know from the local argument in the main text that $\left.\frac{d \Omega_{g}}{d e_{g}}\right|_{N E}>0$. Given that $\Omega_{g}\left(e_{g}, p\left(e_{g}\right)\right)$ is concave in $e_{g}$, it follows immediately that $e_{g}^{A}>e_{g}^{N}$. A continuity argument can then be used to extend this result to the case where countries are sufficiently close to symmetric.

(ii) Suppose that $\sigma_{i g}$ is constant in the price for all $i$ and $g$. It is then immediate from equations (10) and (13) that $e_{i g}^{A}>e_{i g}^{N}$. A continuity argument can then be used to extend this result to the case where the demand semi-elasticities $\sigma_{i g}$ do not vary too much with the price.

(iii) Let $\gamma_{i g}=\gamma_{g} \nu_{i g}$ (with $\nu_{i g}>0$ for all $i$ and $g$ ) and consider the limit as $\gamma_{g} \rightarrow \infty$. We will prove that $\lim _{\gamma_{g} \rightarrow \infty} e_{i g}^{A}=\infty$. Recalling that $e_{i g}^{N}$ is independent of $\gamma_{i g}$, we will conclude that the agreement loosens all standards if $\gamma_{i g}$ is sufficiently large. With some simple algebra we can write:

$$
e_{i g}^{A}=-\frac{\sigma_{i g}}{2}+\sqrt{\left(\frac{\sigma_{i g}}{2}\right)^{2}+\frac{1}{a_{i g}}\left(1+\gamma_{g} \cdot \frac{\sigma_{i g} \int_{j} \nu_{j g} y_{j g}}{\int_{j}\left(y_{j g} \varepsilon_{j g}+d_{j g} \sigma_{j g}\right)}+\frac{\sigma_{i g} \int_{j} a_{j g} e_{j g}^{A} \sigma_{j g} d_{j g}}{\int_{j}\left(y_{j g} \varepsilon_{j g}+d_{j g} \sigma_{j g}\right)}\right)}
$$

Note that all the terms inside the square root are positive, and $\sigma_{i g}$ is bounded by assumption, so if we can show that $\frac{\sigma_{i g} \int_{j} \nu_{j g} y_{j g}}{\int_{j}\left(y_{j g} \varepsilon_{j g}+d_{j g} \sigma_{j g}\right)}$ is bounded away from zero we can conclude that $\lim _{\gamma_{g} \rightarrow \infty} e_{i g}^{A}=\infty$. To see why this is indeed the case, first recall our assumption that $\sigma_{i g}$ and $\varepsilon_{i g}$ are bounded above and bounded away from zero. Next note that $e_{i g}^{A}$ cannot go to zero for any country as $\gamma_{g} \rightarrow \infty$, because this would imply that production costs go to infinity, and this clearly cannot be optimal. Given that $e_{i g}^{A}$ is bounded away from zero for all $i$, it is easy to argue using the market clearing condition that the world price $\left(p_{g}\right)$ and consumer prices $\left(p_{g}+\frac{1}{e_{i g}}\right)$ are bounded above and bounded away from zero as $\gamma_{g} \rightarrow \infty$. This in turn implies that $d_{i g}$ and $y_{i g}$ are bounded above and bounded away from zero. We can conclude that $\frac{\sigma_{i g} \int_{j} \nu_{j g} y_{j g}}{\int_{j}\left(y_{j g} \varepsilon_{j g}+d_{j g} \sigma_{j g}\right)}$ is bounded away from zero, hence the claim. QED

\section{Proof of Proposition 4}


Before proving the more general result stated in Proposition 4, we focus on the case of symmetric countries and prove the stronger result illustrated in Figure 1.

(i) We now show that, if countries are symmetric, there exists a cutoff value $\bar{\gamma}_{g}$ such that $\Delta_{g}>0$ for $\gamma_{g}<\bar{\gamma}_{g}$ and $\Delta_{g}<0$ for $\gamma_{g}>\bar{\gamma}_{g}$.

We begin by characterizing $e_{g}^{N}, e_{g}^{W}$, and $e_{g}^{A}$ as functions of $\gamma_{g}$. It is immediate that $\frac{d e_{g}^{N}}{d \gamma_{g}}=0, \frac{d e_{g}^{W}}{d \gamma_{g}}=0$, and that $e_{g}^{A}=e_{g}^{W}$ for $\gamma_{g}=0$

Next we show that $e_{g}^{A}$ is increasing in $\gamma_{g}$. Let $\tilde{\Omega}_{g}\left(e_{g}, \gamma_{g}\right) \equiv \Omega_{g}\left(e_{g}, p\left(e_{g}\right), \gamma_{g}\right)$ (with a slight abuse of notation we have emphasized the dependence of $\Omega_{g}$ on $\gamma_{g}$ ), and note that $\frac{d e_{g}^{A}}{d \gamma_{g}}=$ $-\frac{d^{2} \tilde{\Omega}_{g}}{d e_{g} d \gamma_{g}} / \frac{d^{2} \tilde{\Omega}_{g}}{d e_{g}^{2}}$. The denominator is negative by our concavity assumption. The numerator is positive since $\frac{d^{2} \tilde{\Omega}_{g}}{d e_{g} d \gamma_{g}}=-\frac{y_{g} d_{g}^{\prime}}{e_{g}^{2}\left(y_{g}^{\prime}-d_{g}^{\prime}\right)}>0$. It follows that $\frac{d e_{g}^{A}}{d \gamma_{g}}>0$.

We now turn to characterizing $W_{g}^{N}$ and $W_{g}^{A}$ as functions of $\gamma_{g}$. Note that $\frac{d e_{g}^{N}}{d \gamma_{g}}=0$ implies $\frac{d W_{g}^{N}}{d \gamma_{g}}=0$, and $\frac{d e_{g}^{A}}{d \gamma_{g}}>0$ implies $\frac{d W_{g}^{A}}{d \gamma_{g}}<0$, since $e_{g}^{A}$ maximizes welfare when $\gamma_{g}=0$ and global welfare is concave in $e_{g}$. It follows that $\frac{d \Delta_{g}}{d \gamma_{g}}<0$.

The final step is to show that $\Delta_{g}<0$ for sufficiently large $\gamma_{g}$. Recalling from the proof of the previous proposition that $\lim _{\gamma_{g} \rightarrow \infty} e_{i g}^{A}=\infty$, it is clear that $\lim _{\gamma_{g} \rightarrow \infty} W_{g}^{A}=-\infty$, so there must exist some $\bar{\gamma}_{g}$ such that $\Delta_{g}<0$ for $\gamma_{g}>\bar{\gamma}_{g}$.

(ii) We now allow for asymmetric countries. Recall that we define $\gamma_{i g}=\gamma_{g} \nu_{i g}$ and vary $\gamma_{g}$. With asymmetric countries, it is still trivially true that $\Delta_{g}>0$ for $\gamma_{g}=0$, and thus also for sufficiently low $\gamma_{g}$. Moreover, it is also still true that $\lim _{\gamma_{g} \rightarrow \infty} e_{i g}^{A}=\infty$ for all $i$ and thus $\Delta_{g}<0$ for sufficiently large $\gamma_{g}$. What is no longer guaranteed in the case of asymmetric countries is that $\frac{d e_{i g}^{A}}{d \gamma_{g}}>0$ for all $\gamma_{g}$, so the uniqueness of the cutoff value $\bar{\gamma}_{g}$ is no longer guaranteed. QED

\section{Proof of Proposition 5}

In the main text we established that $\left.\frac{\partial \Omega_{g}}{\partial p_{g}}\right|_{N E}$ is positive if $\gamma_{g}$ is large enough and negative if $\gamma_{g}$ is small enough. Using a similar argument as in the proof of Proposition 3, it is easy to argue that the local agreement tightens all process standards if $\gamma_{g}$ is large enough and loosens all process standards if $\gamma_{g}$ is small enough.

Now we show that this local result holds globally if either (i) countries are sufficiently close to symmetric or (ii) supply semi-elasticities $\varepsilon_{i g}$ do not vary too much with the price. Furthermore we show that (iii) the globally optimal agreement tightens all standards if $\gamma_{g}$ is large enough, without the need of further conditions.

(i) Suppose that countries are symmetric and denote the common standard by $z_{g}$. We 
know from the local result that $\left.\frac{d \Omega_{g}}{d z_{g}}\right|_{N E}>0$ if $\gamma_{g}$ is sufficiently small and $\left.\frac{d \Omega_{g}}{d z_{g}}\right|_{N E}<0$ if $\gamma_{g}$ is sufficiently large. Our assumption that $\Omega_{g}\left(z_{g}, p\left(z_{g}\right)\right)$ is concave in $z_{g}$ then immediately implies $z_{g}^{A}>z_{g}^{N}$ if $\gamma_{g}$ is sufficiently small and $z_{g}^{A}<z_{g}^{N}$ if $\gamma_{g}$ is sufficiently large. A continuity argument extends this result to the case where countries are sufficiently close to symmetric.

(ii) Suppose that $\varepsilon_{i g}$ is constant in the price for all $i$ and $g$. We know that $\lambda_{g}<0$ if $\gamma_{g}$ is sufficiently small and $\lambda_{g}>0$ if $\gamma_{g}$ is sufficiently large. It is then immediate from comparing equations (16) and (19) that $z_{g}^{A}>z_{g}^{N}$ if $\gamma_{g}$ is sufficiently small and $z_{g}^{A}<z_{g}^{N}$ if $\gamma_{g}$ is sufficiently large. A continuity argument extends this result to the case where supply semi-elasticities $\varepsilon_{i g}$ do not vary too much with the price.

(iii) Recall first that

$$
\begin{aligned}
z_{i g}^{N} & =-\frac{\varepsilon_{i g}}{2}+\sqrt{\left(\frac{\varepsilon_{i g}}{2}\right)^{2}+\frac{1}{b_{i g}}\left(1+\gamma_{g} \nu_{i g}\right)} \\
\text { and } z_{i g}^{A} & =-\frac{\varepsilon_{i g}}{2}+\sqrt{\left(\frac{\varepsilon_{i g}}{2}\right)^{2}+\frac{1}{b_{i g}}\left(1+\gamma_{g} \nu_{i g}-\frac{\varepsilon_{i g} \int_{j} y_{j g}\left(\gamma_{g} \nu_{i g}-b_{j g} z_{j g}^{A} \varepsilon_{j g}\right)}{\int_{j} \varepsilon_{j g} y_{j g}+\int_{j} \sigma_{j g} d_{j g}}\right)}
\end{aligned}
$$

Using a similar argument as in the proof of Proposition 3 one can show that $d_{i g}$ and $y_{i g}$ are bounded above and bounded away from zero as $\gamma_{g} \rightarrow \infty$, and we have assumed that $\sigma_{i g}$ and $\varepsilon_{i g}$ are bounded above and bounded away from zero. Thus to prove the claim it suffices to show that

$$
\lim _{\gamma_{g} \rightarrow \infty} \frac{\int_{j} y_{j g}\left(\gamma_{g} \nu_{j g}-b_{j g} z_{j g}^{A} \varepsilon_{j g}\right)}{\int_{j} \varepsilon_{j g} y_{j g}+\int_{j} \sigma_{j g} d_{j g}}>0
$$

Suppose by contradiction that the above limit is negative. Then, using the fact that all terms other than $\gamma_{g}$ and $z_{i g}^{A}$ are bounded above and bounded away from zero, this would imply that $z_{i g}^{A}$ increases at least with linear speed as $\gamma_{g} \rightarrow \infty$. Then the expression in (23) would increase at most with linear speed. But then the expression for $z_{i g}^{A}$ in (22) would imply that $z_{i g}^{A}$ increases at most with the speed of the square root, a contradiction. The claim thus follows. QED

\section{Proof of Proposition 6}

Before proving the more general result stated in Proposition 6, we prove the stronger result illustrated in Figure 2 for the special case of symmetric countries and constant semielasticities.

(i) Suppose that countries are symmetric and semi-elasticities are constant. We will show that there exist critical levels $\gamma_{g}^{L}<\gamma_{g}^{H}$ such that the agreement increases welfare if $\gamma_{g}<\gamma_{g}^{L}$, decreases welfare if $\gamma_{g} \in\left(\gamma_{g}^{L}, \gamma_{g}^{H}\right)$, and increases welfare again if $\gamma_{g}>\gamma_{g}^{H}$. 
We begin by characterizing the schedules $z_{g}^{N}, z_{g}^{W}$, and $z_{g}^{A}$ as functions of $\gamma_{g}$. It is immediate that $z_{g}^{W}>z_{g}^{N}$ at $\gamma_{g}=0$ and $\frac{d z_{g}^{N}}{d \gamma_{g}}>0$. We next show that $\frac{d z_{g}^{N}}{d \gamma_{g}}>\frac{d z_{g}^{A}}{d \gamma_{g}}>0$. Under symmetry, since $y_{g}=d_{g}$ we can write

$$
\begin{aligned}
z_{g}^{A} & =-\frac{\varepsilon_{g}}{2}+\sqrt{\left(\frac{\varepsilon_{g}}{2}\right)^{2}+\frac{1}{b_{g}}\left(1+\gamma_{g}-\lambda_{g} \varepsilon_{g}\right)}, \\
\text { where } \lambda_{g} & =\frac{\gamma_{g}-b_{g} z_{g}^{A} \varepsilon_{g}}{\varepsilon_{g}+\sigma_{g}}
\end{aligned}
$$

It is easy to verify that $\frac{d z_{g}^{A}}{d \gamma_{g}}>0$ and $\frac{d \lambda_{g}}{d \gamma_{g}}>0$. This latter fact immediately implies that $\frac{d z_{g}^{N}}{d \gamma_{g}}>\frac{d z_{g}^{A}}{d \gamma_{g}}$.

We are now ready to show that there exist cutoffs $\gamma_{g}^{L}<\gamma_{g}^{H}$ such that $\Delta_{g}>0$ if $\gamma_{g}<\gamma_{g}^{L}$ or $\gamma_{g}>\gamma_{g}^{H}$ and $\Delta_{g}<0$ if $\gamma_{g} \in\left(\gamma_{g}^{L}, \gamma_{g}^{H}\right)$.

Let $\gamma_{g}^{M}$ denote the value of $\gamma_{g}$ such that the noncooperative standard is efficient, that is $z_{g}^{N}=z_{g}^{W}$, and let $\gamma_{g}^{H}$ denote the value of $\gamma_{g}$ such that $z_{g}^{N}=z_{g}^{A}$. Clearly, we have $\Delta_{g}>0$ at $\gamma_{g}=0, \Delta_{g}<0$ at $\gamma_{g}=\gamma_{g}^{M}$, and $\Delta_{g}=0$ at $\gamma_{g}=\gamma_{g}^{H}$. Note also that $W_{g}$ is increasing in $z_{g}$ for $z_{g}<z_{g}^{W}$ and decreasing in $z_{g}$ for $z_{g}>z_{g}^{W}$, given that $z_{g}^{W}$ maximizes $W_{g}$ and $W_{g}$ is concave in $z_{g}$.

For $\gamma_{g} \in\left[0, \gamma_{g}^{M}\right)$, clearly $\frac{d W_{g}^{A}}{d \gamma_{g}}<0$ and $\frac{d W_{g}^{N}}{d \gamma_{g}}>0$, and hence $\frac{d \Delta_{g}}{d \gamma_{g}}<0$, so there exists a critical value $\gamma_{g}^{L}$ between 0 and $\gamma_{g}^{M}$ such that $\Delta_{g}>0$ for $\gamma_{g} \in\left[0, \gamma_{g}^{L}\right)$ and $\Delta_{g}<0$ for $\gamma_{g} \in\left(\gamma_{g}^{L}, \gamma_{g}^{M}\right]$. Next note that for $\gamma_{g} \in\left[\gamma_{g}^{M}, \gamma_{g}^{H}\right)$ it must be $\Delta_{g}<0$. Finally note that for $\gamma_{g}>\gamma_{g}^{H}$ it must be $\Delta_{g}>0$, given that $W_{g}$ is decreasing in $z_{g}$ for $z_{g}>z_{g}^{W}$ and $z_{g}^{W} \leq z_{g}^{N} \leq z_{g}^{A}$.

(ii) We now prove the more general result stated in Proposition 6 allowing for asymmetric countries and variable semi-elasticities.

Clearly, it is still true that $\Delta_{g}>0$ for $\gamma_{g}=0$, and thus also for sufficiently low $\gamma_{g}$. In the following, we show that $\lim _{\gamma_{g} \rightarrow \infty} \Delta_{g}>0$. The possibility that $\Delta_{g}$ may be negative for intermediate values of $\gamma_{g}$ follows from part (i) of this proof.

We follow a similar approach as in our proof of Proposition 2. Let $\left(\left\{\hat{z}_{i g}\left(\kappa_{g}\right)\right\}, \hat{p}_{g}\left(\kappa_{g}\right)\right)$ be the solution to the following system:

$$
\begin{gathered}
z_{i g}=-\frac{\varepsilon_{i g}(\cdot)}{2}+\sqrt{\left[\frac{\varepsilon_{i g}(\cdot)}{2}\right]^{2}+\frac{1}{b_{i g}}\left[1+\gamma_{i g}-\kappa_{g} \varepsilon_{i g}(\cdot)\right]} \text { for all } i \\
\int_{i} y_{i g}\left(p_{g}-\frac{1}{z_{i g}}\right)=\int_{i} d_{i g}\left(p_{g}\right)
\end{gathered}
$$

The interpretation of the parameter $\kappa_{g}$ again is that it "connects" the noncooperative equilibrium with the cooperative solution. When $\kappa_{g}=0$ the solution of the above system is the 
noncooperative equilibrium, and when $\kappa_{g}=\lambda_{g}$ it coincides with the cooperative solution. We can trace how global welfare changes as $\kappa_{g}$ changes. The global welfare associated with $\left(\left\{\hat{z}_{i g}\left(\kappa_{g}\right)\right\}, \hat{p}_{g}\left(\kappa_{g}\right)\right)$ can be written as

$$
\hat{W}_{g}\left(\kappa_{g}\right)=\int_{i}\left[\pi_{i g}\left(\hat{p}_{g}-\frac{1}{\hat{z}_{i g}}\right)+S_{i g}\left(\hat{p}_{g}\right)-b_{i g} \hat{z}_{i g} y_{i g}\left(\hat{p}_{g}-\frac{1}{\hat{z}_{i g}}\right)\right],
$$

where we keep in mind, here and below, that $\hat{p}_{g}$ and $\hat{\tau}_{i g}$ are functions of $\kappa_{g}$. Differentiating with respect to $\kappa_{g}$, we obtain

$$
\frac{\partial \hat{W}_{g}}{\partial \kappa_{g}}=\int_{i}\left(y_{i g} \frac{1}{\hat{z}_{i g}^{2}}-b_{i g} y_{i g}^{\prime} \frac{1}{\hat{z}_{i g}}-b_{i g} y_{i g}\right) \frac{\partial \hat{z}_{i g}}{\partial \kappa_{g}}-\int_{i} b_{i g} \hat{z}_{i g} y_{i g}^{\prime} \frac{\partial \hat{p}_{g}}{\partial \kappa_{g}},
$$

which can be simplified using the market clearing condition to

$$
\frac{\partial \hat{W}_{g}}{\partial \kappa_{g}}=\int_{i}\left(y_{i g} \frac{1}{\hat{z}_{i g}^{2}}-b_{i g} y_{i g}^{\prime} \frac{1}{\hat{z}_{i g}}-b_{i g} y_{i g}+\frac{\int_{j} b_{j g} \hat{z}_{j g} y_{j g}^{\prime}}{\int_{j}\left(y_{j g}^{\prime}-d_{j g}^{\prime}\right)} y_{i g}^{\prime} \frac{1}{\hat{z}_{i g}^{2}}\right) \frac{\partial \hat{z}_{i g}}{\partial \kappa_{g}},
$$

and further simplified by plugging the expression for $\hat{z}_{i g}$ from (24), to obtain:

$$
\frac{\partial \hat{W}_{g}}{\partial \kappa_{g}}=\int_{i} \frac{y_{i g}}{\hat{z}_{i g}^{2}}\left(\frac{\int_{j} b_{j g} \hat{z}_{j g} y_{j g} \varepsilon_{j g}}{\int_{j}\left(y_{j g} \varepsilon_{j g}+d_{j g} \sigma_{j g}\right)} \varepsilon_{i g}+\kappa_{g} \varepsilon_{i g}-\nu_{i g} \gamma_{g}\right) \frac{\partial \hat{z}_{i g}}{\partial \kappa_{g}} .
$$

Invoking a similar limit argument as in part (iii) of the proof of Proposition 5, it is easy to see that the term in the large brackets is negative for sufficiently large $\gamma_{g}$. This is clearly true for any fixed $\kappa_{g} \in\left[0, \lambda_{g}\right)$. Let us check if it is true also at the endpoint $\kappa_{g}=\lambda_{g}$. We can write:

$$
\left.\frac{\partial \hat{W}_{g}}{\partial \kappa_{g}}\right|_{\kappa_{g}=\lambda_{g}}=-\gamma_{g} \int_{i} \frac{y_{i g}}{\hat{z}_{i g}^{2}}\left(\nu_{i g}-\frac{\varepsilon_{i g} \int_{j} y_{j g} \nu_{j g}}{\int_{j} \varepsilon_{j g} y_{j g}+\int_{j} \sigma_{j g} d_{j g}}\right) \frac{\partial \hat{z}_{i g}}{\partial \kappa_{g}}
$$

Note that our assumptions imply $\nu_{i g}>\frac{\varepsilon_{i g} \int_{j} y_{j g} \nu_{j g}}{\int_{j} \varepsilon_{j g} y_{j g}+\int_{j} \sigma_{j g} d_{j g}}$. If this inequality were not satisfied, the system of equations (19) defining $z_{i g}^{A}$ would have no solution, violating our assumption that such solution does exist. This can be seen from the expression for $z_{i g}^{A}$ in (22): if $\nu_{i g}<\frac{\varepsilon_{i g} \int_{j} y_{j g} \nu_{j g}}{\int_{j} \varepsilon_{j g} y_{j g}+\int_{j} \sigma_{j g} d_{j g}}$ and $\lambda_{g}$ is large enough, it is easy to argue that the argument of the square root is negative.

Recalling from Proposition 5 that the agreement tightens all process standards for sufficiently large $\gamma_{g}$, we have $\frac{\partial \hat{z}_{i g}}{\partial \kappa_{g}}<0$ for all $i$, and thus $\frac{\partial \hat{W}_{g}}{\partial \kappa_{g}}>0$ along the entire path $\kappa_{g} \in\left[0, \lambda_{g}\right]$ for sufficiently large $\gamma_{g}$. It follows that the welfare change from the agreement is positive since $W_{g}^{A}-W_{g}^{N}=\int_{0}^{\lambda_{g}} \frac{\partial \hat{W}_{g}}{\partial \kappa_{g}} d \kappa_{g}$. QED 


\section{References}

[1] Bagwell, K. and R. Staiger. 1999. "An Economic Theory of GATT." American Economic Review 89(1): 215-248.

[2] Bagwell, K. and R. Staiger. 2001. "Domestic Policies, National Sovereignty, and International Economic Institutions." Quarterly Journal of Economics 116(2): 519-562.

[3] Bagwell, K. and R. Staiger. 2011. "What Do Trade Negotiators Negotiate About? Empirical Evidence from the WTO." American Economic Review 101(4), 1238-73.

[4] Baldwin, R. 1987. "Politically Realistic Objective Functions." Economics Letters 24(3): 287-290.

[5] Blanchard, E. 2010. "Reevaluating the Role of Trade Agreements: Does Investment Globalization Make the WTO Obsolete?" Journal of International Economics 82: 6372 .

[6] Blanchard, E., C. Bown and R. Johnson. 2018. "Global Value Chains and Trade Policy." Mimeo.

[7] Costinot, A. 2008. "A Comparative Institutional Analysis of Agreements on Product Standards." Journal of International Economics 75(1), 197-213.

[8] Drazen, A. and N. Limao. 2008. "A Bargaining Theory of Inefficient Redistribution Policies." International Economic Review 49(2): 621-657.

[9] Grossman, G. and E. Helpman. 1994. "Protection For Sale." American Economic Review 84(4): 833-50.

[10] Grossman, G. and E. Helpman. 1995a. "Trade Wars and Trade Talks." Journal of Political Economy 103(4): 675-708.

[11] Grossman, G. and E. Helpman. 1995b. "The Politics of Free Trade Agreements." American Economic Review 85(4): 667-690.

[12] Grossman, G., P. McCalman and R. Staiger. 2019. "The "New" Economics of Trade Agreements: From Trade Liberalization to Regulatory Convergence?." NBER Working Paper No. 26132. 
[13] Lazarevski, G. 2018. "How Trade Agreements Reduce Political Protectionism." Mimeo.

[14] Levy, P. 1999. "Lobbying and International Cooperation in Tariff Setting." Journal of International Economics 47: 345-370.

[15] Ludema, R. and A. Mayda. 2013. "Do Terms-of-Trade Effects Matter for Trade Agreements? Theory and Evidence from WTO Countries." Quarterly Journal of Economics 128(4): 1837-1893.

[16] Maggi, G. 2019. "Anti-lobbying Gains from International Agreements." Mimeo.

[17] Maggi, G. 2014. "International Trade Agreements," in G. Gopinath, E. Helpman and K. Rogoff (eds.), The Handbook of International Economics, vol. 4, Elsevier.

[18] Maggi, G. and A. Rodriguez-Clare. 1998. "The Value of Trade Agreements in the Presence of Political Pressures." Journal of Political Economy 106(3): 574-601.

[19] Maggi, G. and A. Rodriguez-Clare. 2007. "A Political Economy Theory of Trade Agreements." American Economic Review 97(4): 1374-1406.

[20] Mei, Y. 2019. "Regulatory Protection and the Role of International Cooperation." Mimeo.

[21] Mitra, D. 2002. "Endogenous Political Organization and the Value of Trade Agreements." Journal of International Economics 57(2), August 2002: 473-485.

[22] Nicita, A., M. Olarreaga, and P. Silva. 2018. "Cooperation in WTO's Tariff Waters?" Journal of Political Economy 126(3): 1302-1338.

[23] Ornelas, E. 2005 "Rent Destruction and the Political Viability of Free Trade Agreements." Quarterly Journal of Economics 120(4): 1475-1506.

[24] Ornelas, E. 2008. "Feasible Multilateralism and the Effects of Regionalism." Journal of International Economics, 74(1): 202-224.

[25] Rodrik, D. 2018. "What Do Trade Agreements Really Do?". Journal of Economic Perspectives $32(2)$ : $73-90$. 